\title{
Neuron-Oligodendrocyte Interactions in the Structure and Integrity of Axons
}

\author{
Greg J. Duncan ${ }^{1 *}$, Tyrell J. Simkins ${ }^{1,2,3}$ and Ben Emery ${ }^{1}$ \\ 1 Jungers Center for Neurosciences Research, Department of Neurology, Oregon Health \& Science University, Portland, OR, \\ United States, ${ }^{2}$ Vollum Institute, Oregon Health \& Science University, Portland, OR, United States, ${ }^{3}$ Department \\ of Neurology, VA Portland Health Care System, Portland, OR, United States
}

OPEN ACCESS

Edited by:

Tim Czopka,

University of Edinburgh,

United Kingdom

Reviewed by:

Rafael Góis Almeida,

University of Edinburgh,

United Kingdom

Aiman S. Saab,

University of Zurich, Switzerland

*Correspondence:

Greg J. Duncan

duncangr@ohsu.edu

Specialty section:

This article was submitted to

Molecular Medicine,

a section of the journal

Frontiers in Cell and Developmental

Biology

Received: 13 January 2021

Accepted: 15 February 2021

Published: 08 March 2021

Citation:

Duncan GJ, Simkins TJ and Emery B (2021)

Neuron-Oligodendrocyte Interactions in the Structure and Integrity of Axons.

Front. Cell Dev. Biol. 9:653101.

doi: 10.3389/fcell.2021.653101
The myelination of axons by oligodendrocytes is a highly complex cell-to-cell interaction. Oligodendrocytes and axons have a reciprocal signaling relationship in which oligodendrocytes receive cues from axons that direct their myelination, and oligodendrocytes subsequently shape axonal structure and conduction. Oligodendrocytes are necessary for the maturation of excitatory domains on the axon including nodes of Ranvier, help buffer potassium, and support neuronal energy metabolism. Disruption of the oligodendrocyte-axon unit in traumatic injuries, Alzheimer's disease and demyelinating diseases such as multiple sclerosis results in axonal dysfunction and can culminate in neurodegeneration. In this review, we discuss the mechanisms by which demyelination and loss of oligodendrocytes compromise axons. We highlight the intra-axonal cascades initiated by demyelination that can result in irreversible axonal damage. Both the restoration of oligodendrocyte myelination or neuroprotective therapies targeting these intra-axonal cascades are likely to have therapeutic potential in disorders in which oligodendrocyte support of axons is disrupted.

Keywords: oligodendrocyte, remyelination, axonal degeneration, demyelination, multiple sclerosis, Wallerian degeneration, mitochondria

\section{INTRODUCTION}

Structural variants of the myelin sheath have arisen several times during evolution as a means to allow for the rapid conduction of nerve impulses along axons, including in vertebrates and some species of worm and shrimp (Roots, 2008). Within the central nervous system (CNS) of jawed vertebrates, myelination is carried out by oligodendrocytes, a highly specialized glial cell (Zalc, 2016). The promotion of the speed and efficiency of action potentials has been the best understood purpose of oligodendrocytes and myelin over the past seven decades (Hartline and Colman, 2007). While this role is undeniably important, there is also an increasing appreciation that neurons require support by glia, including oligodendrocytes, for their longterm integrity. When oligodendroglial support is lost, axons become progressively compromised and vulnerable to loss. Consequently, remyelination strategies are being pursued in diseases such as multiple sclerosis (MS) with the hope of not only recovering nerve conduction in the short term but also protecting axons against degeneration in the long term (Franklin et al., 2012; Franklin and Ffrench-Constant, 2017; Lubetzki et al., 2020b). In this review, we outline evidence emerging from both animal models and human pathology that suggests that 
the integrity of myelinated neurons is dependent on oligodendrocyte support. We focus on recent advances in our understanding of the cellular mechanisms by which oligodendrocytes support axonal and neuronal integrity, how neurons adapt to demyelination, and the intra-axonal cascades contributing to their degeneration.

\section{DEMYELINATION AND NEURONAL DAMAGE; BEYOND CLASSICAL DEMYELINATING DISEASES}

Disruption of oligodendrocyte-axon contact and demyelination causes dysfunction in a wide-range of neurological pathologies. MS is considered the prototypical CNS demyelinating disease and features myelin loss in lesions throughout the gray and white matter. Clinically, MS typically presents as a relapsing-remitting (RRMS) course of neurologic dysfunction, though occasionally people with MS experience a progressive accumulation of neurologic disability with few or no relapses (primary progressive MS, PPMS). Demyelination is not the only sequalae in MS; there is also considerable brain atrophy (De Stefano et al., 2010), which is reflective of ongoing axonal damage and neurodegeneration. Acute demyelinating lesions have the highest rate of axonal damage and the degree of damage is correlated with inflammation (Ferguson et al., 1997; Bitsch et al., 2000; Kornek et al., 2000; Kuhlmann et al., 2002). Cytotoxic T-cells found within these lesions can directly damage neurons (Medana et al., 2001; Yan et al., 2003; Shriver and Dittel, 2006) and drugs targeting the activation and infiltration of adaptive immune cells in the CNS are effective at reducing relapses (Derfuss et al., 2020). However, these drugs typically fail to prevent the accumulation of progressive disability during chronic phases of the disease (secondary progressive, SPMS), when acute T-cell mediated lesions wane. Instead, it is the widespread loss of axons and neurons during the progressive phase of the disease that drives permanent disability (Fu et al., 1998; Bjartmar et al., 2000; De Stefano et al., 2001). Crucially, remyelination fails to regenerate myelin along the majority of demyelinated axons leaving them chronically demyelinated (Patrikios et al., 2006; Goldschmidt et al., 2009). These chronically demyelinated inactive lesions constitute the bulk of lesions in MS (Frischer et al., 2015) and display signs of ongoing axonal damage (Kornek et al., 2000). Axonal damage in these chronically demyelinated lesions is, therefore, likely the central contributor to persistent disability in MS.

The susceptibility of axons to damage following myelin and oligodendrocyte loss is observed in other demyelinating pathologies as well. Leukodystrophies are a heterogeneous group of genetic disorders characterized by abnormalities in the development or maintenance of CNS myelin (Kohler et al., 2018; van der Knaap et al., 2019; Wolf et al., 2020). Adrenoleukodystrophy (ALD) is an X-linked demyelinating leukodystrophy caused by mutation in the ABCD1 gene (Mosser et al., 1993), which encodes an ATP-binding cassette transporter necessary for very long-chain fatty acid (VLCFA) transport into the peroxisome for degradation (McGuinness et al., 2003; van Roermund et al., 2011; Wiesinger et al., 2013). As a consequence, there is an accumulation of VLCFA in cells leading to increased oxidative stress culminating in myelin loss as well as progressive axonal degeneration (Powers et al., 2000; Fourcade et al., 2008). Whether the progressive axonal degeneration occurring in ALD is a primary or secondary to myelin degeneration has not been fully determined. However, peroxisome impairment via the deletion of Pex5 selectively from oligodendrocyte lineage cells results in the accumulation of VLCFA and axonal degeneration, demonstrating that axonal degeneration can, in principal, be secondary to oligodendrocytic peroxisomal dysfunction (Kassmann et al., 2007). PelizaeusMerzbacher disease (PMD) is an X-linked hypomyelinating leukodystrophy caused by mutation, deletion or duplication of the PLP1 gene. PLP1, which encodes proteolipid protein (PLP) and its alternative splicing variant DM20, are the most abundant myelin proteins (Jahn et al., 2020). PMD patients typically have a global developmental delay (motor and cognitive) as well as hypotonia, spasticity, and ataxia (Inoue, 2019). PLP1 gene duplication is the most common cause of PMD (Mimault et al., 1999). Rodent models of homozygous $P l p 1$ gene duplication result in premature arrest of myelination and oligodendrocyte apoptosis likely as a result of PLP and cholesterol accumulation leading to endoplasmic reticulum (ER) stress (Kagawa et al., 1994; Readhead et al., 1994; Simons et al., 2002; Karim et al., 2007; Elitt et al., 2018). Mice hemizygous for the PLP gene duplications myelinate normally before developing significant demyelination, inflammation and axonal degeneration (Anderson et al., 1998; Ip et al., 2006). Ultrastructural examination of clinical gene duplications also reveal considerable axonal damage and degeneration (Laukka et al., 2016). The examples of PMD and ALD highlight that neuronal integrity is often impaired in genetic demyelinating pathologies.

Myelin loss and axonal damage are also features of a number of neurologic conditions less commonly thought of as myelinrelated disorders. In Alzheimer's disease (AD), white matter damage is one of the earliest pre-clincal pathologic changes (Hoy et al., 2017; Nasrabady et al., 2018). Single-cell and spatial transcriptomic analyses reveal upregulation of genes involved in remyelination in AD brains (Grubman et al., 2019; Mathys et al., 2019; Agarwal et al., 2020; Chen et al., 2020). However, late term senescent plaques may be inhibitory for remyelination and potentially co-op oligodendrocyte progenitor cells (OPCs) into a pro-inflammatory role (Zhang et al., 2019). These human and rodent studies highlight an underappreciated involvement of oligodendrocyte lineage cells in the pathophysiology of AD. Likewise, the neurodegenerative disorder amyotrophic lateral sclerosis (ALS) also features myelin damage. Decreased expression of myelin basic protein (MBP) in the motor cortex and spinal cord is observed in ALS (Kang et al., 2013). Animal models with mutant Sod1, which recapitulate the motor neuron loss observed in ALS, have increased oligodendrocyte loss coupled with a failure of new oligodendrocytes to mature (Kang et al., 2013; Philips et al., 2013). In zebrafish models this precedes motor neuron degeneration, suggesting myelin and oligodendrocyte dysfunction is an early pathology in ALS (Kim et al., 2019). Knockout of mutant Sod1 from OPCs delays motor decline and 
increases survival time, possibly by restoring oligodendrocyte support to the neuron (Lee et al., 2012; Kang et al., 2013). Beyond ALS and AD, traumatic injuries to both the brain and spinal cord exhibit conduction deficits and acute demyelination (Kakulas, 2004; Guest et al., 2005; James et al., 2011; Marion et al., 2018) which may also strip axons of oligodendrocyte support and leave them vulnerable to degeneration. However, few axons following spinal cord injury remain chronically demyelinated (Kakulas, 2004; Lasiene et al., 2008). Whether this is due to subsequent degeneration of demyelinated axons or efficient remyelination remains unclear (Duncan et al., 2020). Demyelination and oligodendrocyte loss is also observed in ischemic stroke (Rosenzweig and Carmichael, 2013; Sozmen et al., 2016), and improved myelin regeneration is associated with enhanced functional recovery (Sozmen et al., 2016). This suggests a functional role of demyelination in the deficit following ischemia, at least in rodent models. The breakdown of oligodendroglial support to neurons and demyelination may be common to a wide range of disorders. For these reasons, it is crucial to understand how oligodendrocytes shape axonal function and support their long-term survival.

\section{MYELINATING GLIA ORGANIZE THE AXON}

Oligodendrocyte progenitor cells differentiate to form mature oligodendrocytes which extend multiple processes that ensheath nearby axons with concentric layers of membrane (for comprehensive reviews on the development and structure of CNS myelin see Aggarwal et al., 2011; Rasband and Peles, 2015; Simons and Nave, 2016; Stassart et al., 2018; Stadelmann et al., 2019). Depending on the CNS region, each oligodendrocyte will myelinate somewhere between 20 and 60 axons, with myelin internodes being from 20 to $200 \mu \mathrm{m}$ in length (Chong et al., 2012). During myelination, the leading edge of the developing myelin sheath circles repetitively around the axon, remaining closely associated with the axon to pass under previous myelin wraps with each revolution. Meanwhile, the outer wraps extend laterally, with the terminal edges attaching to the axon in a series of loops that ultimately form the paranode. Over time the cytoplasm is excluded from most regions of the myelin, producing compact myelin (Snaidero et al., 2014). Some areas of non-compact myelin remain; the paranodal loops and the innermost "tongue" of myelin adjacent to the axon remain uncompacted, providing an area of oligodendrocyte cytoplasm closely opposed to that of the axon. In addition, cytoplasmic channels extend through the myelin sheath and provide a connection between the oligodendrocyte cell body and the inner myelin layer (Velumian et al., 2011; Snaidero et al., 2014). Although most prominent during development, these cytoplasmic channels remain in the adult (Snaidero et al., 2017) and likely act as an important conduit for organelles and molecules to support the myelin sheath.

An important role of myelin is to establish distinct axonal domains (recently reviewed in detail in Lubetzki et al., 2020a; Rasband and Peles, 2021). The myelinated regions of axons can be divided into subdomains; the internode (corresponding to the compacted region of myelin), the paranodes (where the outer loops of the myelin contact the axon), the node of Ranvier (the $\sim 1 \mu \mathrm{m}$ gap between adjacent myelin internodes) and the juxtaparanode (the interface between the paranode and compact myelin, rich in potassium channels) (Figure 1). During development, the clustering of voltage-gated sodium and potassium channels to these domains coincides with the process of myelination, and is disrupted in dysmyelinating mutants (Rasband et al., 1999; Mathis et al., 2001; Arroyo et al., 2002). Several partially redundant mechanisms act in parallel to drive the clustering of nodal proteins during myelination (Susuki et al., 2013). Firstly, glial secreted proteins such as Contactin 1, Phosphocan, and Tenascin-R help cluster axonal neurofascin 186 and voltage-gated sodium channel subunits to sites of future nodes (Kaplan et al., 1997; Susuki et al., 2013; Freeman et al., 2015; Dubessy et al., 2019; Thetiot et al., 2020). Subsequently, oligodendroglial neurofascin 155 interacts with axonal Contactin 1 and Caspr at the paranodes, establishing septate-like junctions that form a barrier between the axon and the myelin loops that prevents the lateral diffusion of nodal proteins (Rasband et al., 1999; Charles et al., 2002; Susuki et al., 2013). Finally, the nodal and paranodal complexes are stabilized through interactions with the axonal cytoskeleton. These interactions are dependent on proteins such as AnkyrinG and protein 4.1B, which tether nodal and paranodal proteins to axonal spectrins, respectively (Komada and Soriano, 2002; Susuki et al., 2013; Brivio et al., 2017). Voltage-gated potassium channels are predominantly restricted to the juxtaparanodal regions through interactions between glial Contactin 2 and axonal Caspr2 (Poliak et al., 2003; Traka et al., 2003). This localization of voltage-gated ion channels essentially restricts the regeneration of action potentials to the node of Ranvier, with current then flowing longitudinally along the myelinated segments of the axon (Hartline and Colman, 2007; Figure 1). This process, termed saltatory conduction, dramatically increases conduction velocity relative to axonal size (Waxman and Bennett, 1972). Although most work has focused the longitudinal current flow along the interior of the axon, a recent study indicates that conduction velocity is also influenced by current flow through the periaxonal space between the innermost myelin wrap and the axon (Cohen et al., 2020). This may prove to be highly significant in light of findings that the width of this space is regulated by neuronal activity and during learning (Cullen et al., 2021).

\section{OLIGODENDROCYTE SUPPORT OF AXONAL HEALTH}

\section{Oligodendrocytic Shuttling of Monocarboxylates and Glucose to the Axon}

Although the best understood roles of myelin are to allow for rapid saltatory conduction by electrically insulating the axon and establishing distinct axonal domains, myelination also has profound implications for axonal energy demand 


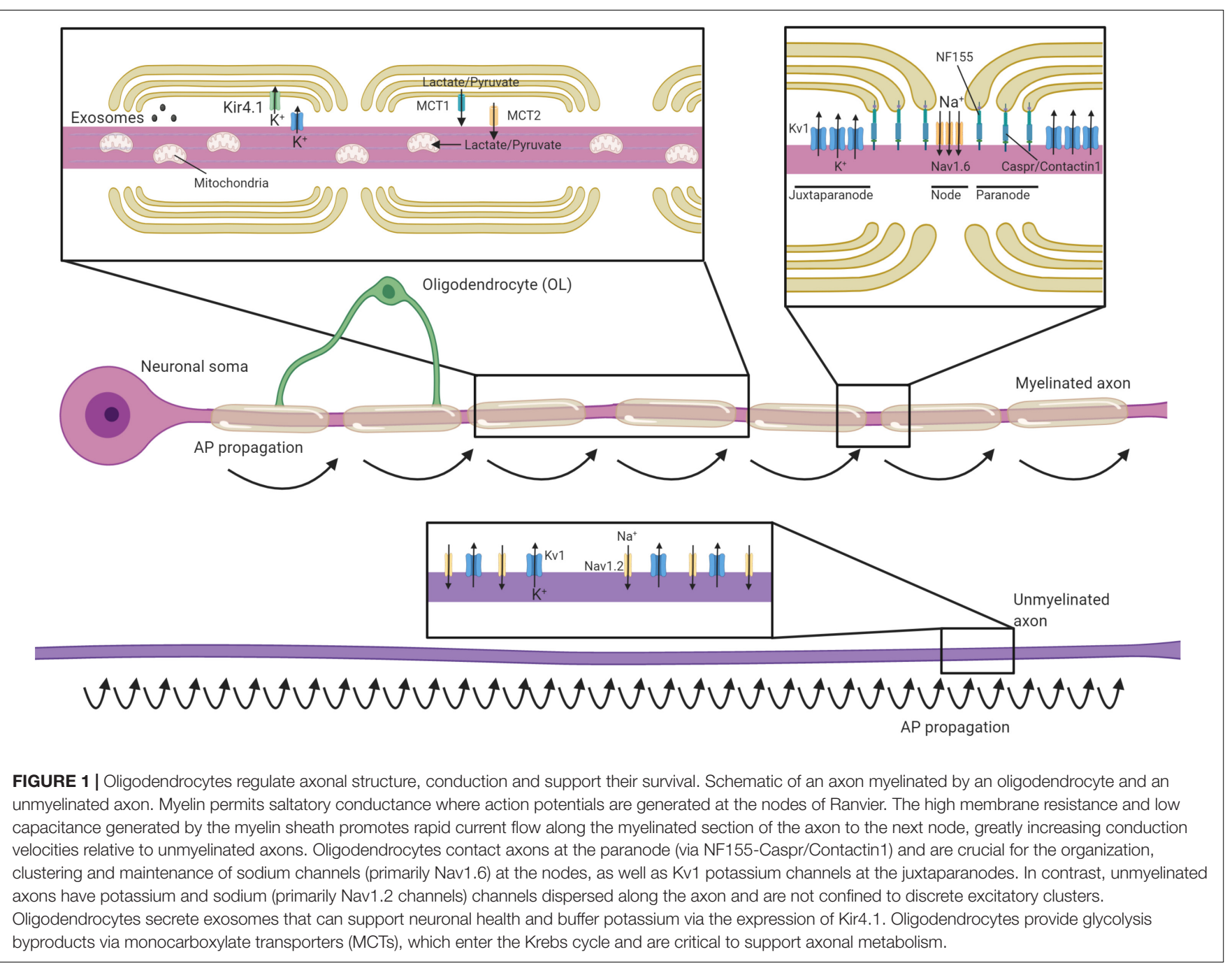

and metabolism. Myelination reduces axonal capacitance and substantially decreases the amount of energy required to restore the resting ion concentrations after each depolarization (Harris and Attwell, 2012). However, myelin, with its concentric membranes, also requires considerable resources to produce and maintain. The act of myelination can be therefore be seen as shifting some of the metabolic load of neuronal firing from axons onto oligodendrocytes. Even though it has been estimated that it may take 15-23 million action potentials for the relative decrease in energy expenditure by a myelinated axon to offset the energetic cost of making the myelin sheath (Harris and Attwell, 2012), this investment may become beneficial at times of high activity where an unmyelinated axon may otherwise struggle to support successive rounds of repolarization through the activity of the $\mathrm{Na}+/ \mathrm{K}+$-ATPase. Nevertheless, as noted in several reviews on the subject (Mierzwa et al., 2010; Nave, 2010; Stassart et al., 2018), the presence of myelin comes with the liability of impeding the axon's ability to take up glucose and other metabolites directly from the extracellular space, as myelin restricts diffusion of most molecules to gaps at the paranodal junctions. Combined with the substantial logistical difficulty of transporting energy sources from the neuronal cell body, myelinated axons may rely on metabolic support from the myelinating glia to meet their energy requirements. Oligodendrocytes express the monocarboxylate transporter MCT-1 and can transfer glycolysis products such as lactate to axons (Figure 1), where it can be converted to ATP (Funfschilling et al., 2012; Lee et al., 2012). MCT-1 is expressed both within the myelin sheath and along the adaxonal surface, ideally placing it to directly supply myelinated axons with energy sources they would otherwise be isolated from Rinholm et al. (2011); Lee et al. (2012). Within the corpus callosum, oligodendrocytes support axonal metabolic function by providing glucose as well as glycolysis products (Meyer et al., 2018). Whether the relative oligodendroglial supply of glucose verses the supply of lactate to axons varies across different regions of the CNS is yet to be systematically investigated. Intriguingly, oligodendrocyte expression of the GLUT1 glucose transporter is regulated by NMDA receptor activity (Saab et al., 2016). Given oligodendrocytes do not store glycogen, this suggests a mechanism by which this oligodendroglial uptake of glucose and subsequent supply of glycolysis products might be matched to levels of activity in the myelinated axons (Micu et al., 2016), 
supporting axons during times of heightened metabolic load (Micu et al., 2017). This feature of supporting axons through provision of glycolysis products would mirror the role of astrocytes and invertebrate glial cells (Pellerin and Magistretti, 1994; Tekkok et al., 2005; Volkenhoff et al., 2015).

Global heterozygosity of the Slc16a1 gene (which encodes the MCT-1 transporter) in mice causes axonal pathology by eight months of age, including axonal swellings, degeneration, and enlarged axonal mitochondria (Lee et al., 2012). In contrast, a more recent study found that conditionally ablating Slc16a1 within mature oligodendrocytes (using MOG-Cre) resulted in a more modest and delayed axonopathy, becoming apparent from postnatal day 750 (Philips et al., 2021). This suggests that some of the neurodegeneration in the global heterozygous mice is likely secondary to expression of monocarboxylate transporters in cell types other than myelinating oligodendrocytes, such as astrocytes. Nevertheless, the late-onset axonal pathology seen in oligodendrocyte conditional knockouts of Slc16a1 clearly indicates that oligodendrocyte provision of metabolites is required for axonal integrity, at least in the aging CNS (Philips et al., 2021). Given (Lee et al., 2012) found reduced expression of MCT1 in the cortex of ALS patients and oligodendrocytes of SOD1 mutants it is tempting to speculate that enhancing oligodendrocyte provision of glycolysis products to axons could be neuroprotective in disease contexts. A recent study seeking to virally overexpress MCT1 in oligodendrocytes in the model failed to find any therapeutic benefit, however (Eykens et al., 2021). This highlights the need for a better understanding of the situations in which oligodendrocyte provision of glycolysis products is a limiting factor for axonal survival.

\section{Extracellular Vesicle Transfer to Axons}

Extracellular vesicles (EVs) are lipid bilayer-bound structures that can carry a variety of cargos including metabolites, proteins, lipids, mRNAs, and miRNAs. Based on size and release mechanisms, they are classed as exosomes [30-100 nm, released from multivesicular bodies (MVBs)] or microvesicles (100-1,000 nm, released by budding of the plasma membrane). Once secreted, EVs can be taken up by other cells, where they modulate cellular phenotypes and gene expression (Holm et al., 2018). Increasing evidence indicates that oligodendrocytederived EVs support neuronal integrity. Oligodendrocyte MVBs, the precursor to released exosomes, are concentrated in regions of non-compact myelin and at the adaxonal loop (Hsu et al., 2010; Fruhbeis et al., 2013). Following secretion, oligodendrocyte EV's are taken up by neurons (Kramer-Albers et al., 2007; Fruhbeis et al., 2013; Mukherjee et al., 2020), and promote their survival, at least in culture (Fruhbeis et al., 2013). Conversely, mice with conditional oligodendrocyte ablation of Rab35 (required for secretion of exosomes from oligodendrocyte MVBs) display progressive oxidative damage and neuronal loss (Hsu et al., 2010; Mukherjee et al., 2020). Somewhat like the expression of glucose transporters (see section "Oligodendrocytic Shuttling of Monocarboxylates and Glucose to the Axon"), the release of EVs from oligodendrocytes is stimulated by activation of oligodendroglial glutamate receptors (Fruhbeis et al., 2013). The release of EVs along the periaxonal space would presumably allow for preferential uptake of oligodendrocyte-released EVs by the myelinated axon, allowing for a relatively targeted and activity-regulated transfer of supportive metabolites or signaling molecules. Such a transfer has been demonstrated to occur between ensheathing glia and the giant squid axon (Buchheit and Tytell, 1992), and likely represents an evolutionarily conserved relationship between glia and axons.

A large number of details remain to be determined about the role of oligodendrocyte exosomes, including their cargo. Oligodendrocyte-derived exosomes are known to be enriched in chaperone proteins and enzymes mediating protection against oxidative stress (Kramer-Albers et al., 2007), but thus far individual components has received little experimental attention. One notable exception is ferritin heavy chain, which is secreted with oligodendrocytes EVs and protects neurons against ferroptotic cell death in vitro (Mukherjee et al., 2020). Oligodendrocyte conditional ablation of the Fth1 gene in mice resulted in neuronal loss and oxidative damage, indicating that at least some of the neurodegeneration seen in the oligodendrocyte Rab35 conditional knockouts may be secondary to loss of ferritin heavy chain secretion (Mukherjee et al., 2020). It should be noted that oligodendroglial expression of ferritin heavy chain is also required for early postnatal myelination (Wan et al., 2020), which raises the potential confounder that some of the axonal degeneration in the Fth 1 condition knockout mice could be secondary to myelin defects. Nevertheless, with conditional ablation of the Fth1 gene in adulthood the neuronal loss occurred in the absence of detectable disruption to myelin (Mukherjee et al., 2020), arguing against this interpretation. Reduced EV release is seen in oligodendrocytes derived from Plp1 and Cnp1 null mice, both of which display progressive axonal degeneration (Frühbeis et al., 2020). Together, these results identify the secretion of EVs from oligodendrocytes as a potentially important mechanism for axonal support by oligodendrocytes.

\section{Potassium Buffering and the Glial Syncytium}

Action potentials rely on differential concentrations of $\mathrm{Na}^{+}$and $\mathrm{K}^{+}$ions across the neuronal membrane, with the extracellular space being relatively high in $\mathrm{Na}^{+}$and low in $\mathrm{K}^{+}$. The repolarization phase of each action potential releases $\mathrm{K}^{+}$into to the extracellular space, which needs to be removed by a network of glial cells to enable subsequent action potentials (Rash, 2010). Astrocytes fulfill this function throughout much of the CNS. However in myelinated fibers, voltage-gated $\mathrm{K}^{+}$channels are primarily localized to the juxtaparanodal region where they can release $\mathrm{K}^{+}$into the periaxonal space underlying the myelin (Wang et al., 1993; Poliak et al., 2003). Oligodendrocytes express the inward-rectifying potassium channel Kir4.1 (coded by the Kcnj10 gene) at the perinodal area and along the inner myelin tongue, where it would be well placed to clear $\mathrm{K}^{+}$from the periaxonal space (Schirmer et al., 2018; Figure 1). Indeed, oligodendrocyte Kcnj10 conditional knockouts display delayed $\mathrm{K}^{+}$clearance from the white matter, deficits in high-frequency axonal firing, and 
seizures (Larson et al., 2018; Schirmer et al., 2018). Interestingly, the failure of oligodendrocytes to clear potassium from the periaxonal space is also crucial for the long-term health of axons. Kcnj10 conditional knockouts display axonal mitochondrial swelling and degeneration in long white matter tracts such as the spinal cord and optic nerve and loss of retinal ganglion cells (RGCs; Schirmer et al., 2018). Oligodendrocytes may rely heavily on gap junctions to siphon potassium away from the inner myelin tongue and into the broader glial syncytium. Heterotypic gap junctions form between oligodendrocytes and astrocytes, predominantly through either oligodendrocyte $\mathrm{Cx} 47$ and astrocyte $\mathrm{Cx} 43$ or oligodendrocyte $\mathrm{Cx} 32$ and astrocyte $\mathrm{Cx} 30$ (Kamasawa et al., 2005; Orthmann-Murphy et al., 2007; Magnotti et al., 2011). These heterotypic junctions could mediate the directional shuttling of potassium from the oligodendrocytes into the astrocytes (Fasciani et al., 2018), though oligodendrocyteoligodendrocyte gap junctions may also help disperse potassium (Kettenmann et al., 1983; Battefeld et al., 2016).

It is likely that the roles of connexin-based channels between glia could extend well beyond potassium buffering. For example, in vitro studies demonstrate that labeled glucose analogs can be trafficked between oligodendrocytes and astrocytes, raising the possibility that gap junctions could mediate similar trafficking of glucose between astrocytes and oligodendrocytes in vivo (Niu et al., 2016). Consistent with this idea, genetic disruption of $\mathrm{Cx} 47$, necessary to fully connect oligodendrocytes to astrocytes, blocks the ability of glucose-loaded corpus callosum oligodendrocytes to support axonal firing in conditions of oxygen and glucose deprivation (Meyer et al., 2018). Similarly, loading thalamic astrocytes with glucose or lactate supports postsynaptic activity during oxygen and glucose deprivation, a protective effect that is blocked by disruption of Cx32 and Cx47 (Philippot et al., 2021). Together, these data indicate gap junctions may serve to link glial networks and distribute metabolites that are ultimately shuttled to axons through oligodendrocytes. Recent findings indicate that astrocytes and oligodendrocytes may also act in concert to regulate the breakdown of glutamate and redistribution of its metabolites, with subsets of oligodendrocytes in the spinal cord and midbrain expressing glutamine synthetase (Philippot et al., 2021). Nevertheless, the metabolites that are trafficked between astrocytes and oligodendrocytes through gap junctions in more physiological contexts have been challenging to experimentally determine, especially given the profound myelin deficits seen in mice lacking $\mathrm{Cx} 47$ and $\mathrm{Cx} 32$ (Menichella et al., 2003). The exact role of these glial gap junctions in supporting axonal health is likely to be an ongoing area of important work.

\section{RELATIONSHIP BETWEEN DE/DYSMYELINATION AND AXONAL LOSS IN RODENT MODELS}

Demyelinating and dysmyelinating animal models have offered key insights into how oligodendrocytes support neurons. Demyelination in rodents is typically produced in one of three ways; via autoimmune attack against myelin, administration of demyelinating toxins, or genetic depletion of oligodendrocytes.
These strategies differ dramatically in the extent of myelin and axonal damage as well as the aspects of MS modeled. A key shared characteristic of these models is the fairly rapid and effective remyelination. At this time no model accurately mimics the stresses placed on the axon by long-term remyelination failure like that seen in MS. Nevertheless, these models have revealed much about the extent to which oligodendrocytes contribute to neuronal integrity.

\section{EAE}

Experimental autoimmune encephalitis (EAE) is a family of models in which the immune system is activated to target the myelin sheath for degradation. Typically this is achieved by the transfer of myelin-reactive $\mathrm{T}$ cells or the administration of myelin peptides alongside adjuvants to drive the immune response (Kipp et al., 2012; Ransohoff, 2012; Lassmann and Bradl, 2017). In recent years, the most common model of EAE involves immunization with the 35-55 peptide of myelin oligodendrocyte glycoprotein $\left(\mathrm{MOG}_{35-55}\right)$, a myelin protein found in the outermost lamellae (Mendel et al., 1995), along with complete Freund's adjuvant and pertussis toxin. In C57BL/6 mice this reliably causes inflammatory demyelinating lesions, mostly within the spinal cord, which are characterized by CD4+T-cell infiltration (Soulika et al., 2009; Berard et al., 2010). Significant axonal damage and subsequent transection occur within the spinal cord (Kim et al., 2006; Aharoni et al., 2011), and are correlated with persistent decline (Wujek et al., 2002; Papadopoulos et al., 2006). Both transport deficits and swellings are observed prior to demyelination and the extent of axonal damage is closely correlated with, and driven by inflammatory infiltrate (Soulika et al., 2009; Nikic et al., 2011; Sorbara et al., 2014). Nevertheless, genetic manipulations of the oligodendrocyte lineage to improve remyelination also enhance axonal preservation following EAE (Mei et al., 2016), indicating oligodendroglial and myelin damage likely contributes to axon loss in this model. However, the stochastic nature of demyelinating lesions in EAE and challenges in uncoupling immunomodulatory effects from remyelination make it difficult to use this model to make mechanistic insights about how oligodendrocytes support axons.

\section{Toxic Models}

Toxin-induced models of demyelination, such as dietary cuprizone or focal injections of lysolecithin (or less commonly ethidium bromide) offer strict spatial and temporal control over demyelination and subsequent remyelination. Lysolecithin is typically injected into white matter tracts where it acts as a detergent to disrupt membranes and induce demyelination (Plemel et al., 2018). This is followed by rapid remyelination of remaining axons (Woodruff and Franklin, 1999). While this model has been an enormously important tool to understand the mechanisms of remyelination, lysolecithin does not act selectively on myelin membranes, but disrupts all membranes often killing astrocytes and triggering calcium accumulation and subsequent degeneration of axons (Zhao et al., 2015; Plemel et al., 2018). The combination of very rapid remyelination, small lesion size and axon damage through the direct action 
of the toxin makes lysolecithin-mediated demyelination an unsuitable model for delving in to how oligodendrocytes support neuronal integrity. Conversely, cuprizone can cause prolonged demyelination throughout the corpus callosum, hippocampus, cortex and the cerebellum for as long as the animals are fed cuprizone (Matsushima and Morell, 2001; Gudi et al., 2014; Bai et al., 2016; Zhan et al., 2020). Cuprizone is a copper chelator, but the precise mechanism by which cuprizone induces demyelination is unclear, though oxidative damage to oligodendrocyte is seen within days of administration of cuprizone followed by both apoptotic and non-apoptotic forms of cell death (Buschmann et al., 2012; Skripuletz et al., 2013; Jhelum et al., 2020). At higher doses, cuprizone is widely toxic to cells, inducing hepatoxicity and spongiform encephalopathy (Suzuki, 1969; Suzuki and Kikkawa, 1969), though damage is most prominent in oligodendrocytes at the doses typically given to induce demyelination. Axon degeneration can be severe with between $20 \%$ and $50 \%$ of the axons lost in the corpus callosum depending on the length and dose of cuprizone administered (Irvine and Blakemore, 2006; Manrique-Hoyos et al., 2012). Interestingly, following withdrawal of cuprizone from the diet there is ongoing damage to axons despite remyelination (Lindner et al., 2009) ultimately culminating in reduced axon number and motor coordination (Manrique-Hoyos et al., 2012). This indicates that even with successful remyelination ongoing axonal injury can occur. Whether the failure to fully protect axons after remyelination is due to an inherent inability of new, remyelinating oligodendrocytes to adequately support axons, an ongoing cytotoxic inflammatory state induced by cuprizone, or persistent toxicity remains unclear.

\section{Genetic Models}

Demyelination can be induced by the genetic targeting of the oligodendrocyte lineage, which avoids the direct action of inflammation or toxins on neurons. This is typically achieved via the inducible expression of "suicide" genes in oligodendrocytes such as diphtheria toxin subunit A (DTA; Traka et al., 2010; Pohl et al., 2011), DTA receptor in conjunction with diphtheria toxin (Oluich et al., 2012), activated caspases (Caprariello et al., 2012), or via the deletion of a key gene for myelin or oligodendrocyte maintenance like Myrf (Koenning et al., 2012; Hartley et al., 2019). Axon swellings are observed prior to and during outright demyelination in the DTA models (Pohl et al., 2011; Oluich et al., 2012) but axonal loss is not observed, at least within the visual system (Traka et al., 2010). Following demyelination, the number of oligodendrocytes recovers and the mice rapidly remyelinate in DTA models (Traka et al., 2010; Pohl et al., 2011). Similarly, genetic mutants that congenitally lack compact myelin such as the Mbp mutant shiverer mice or les rats, do not have progressive axonal loss, and retain ensheathing oligodendrocytes (Rosenbluth, 1980; Griffiths et al., 1998; Smith et al., 2013). These studies illustrate a critical point - loss of myelin per se does not invariably lead to the degeneration of the underlying axon when oligodendroglial support is restored rapidly or retained (as in the case of $M b p$ mutants). Additionally, the cellspecificity of these genetic models will likely be highly beneficial to elucidate mechanisms by which oligodendrocytes support axons, particularly if models with delayed oligodendrogenesis and remyelination can be developed.

\section{Long-Term Breakdown of Oligodendrocyte Support in Myelin Gene Knockouts Leaves Neurons Vulnerable to Damage}

Substantial demyelination in animal models does not invariably lead to neurodegeneration, conversely, germline knockout of several genes expressed solely within the oligodendrocyte lineage go on to develop axonal degeneration despite forming normal levels of myelin. Plp1 null mice develop compact myelin but lack stable intermembrane bonding resulting in separation of the myelin lamellae (Boison and Stoffel, 1994; Rosenbluth et al., 1996; Coetzee et al., 1999). However, outright demyelination remains rare even with aging (Klugmann et al., 1997; Luders et al., 2019). These mice develop profound axonal transport defects and progressive axonal loss, particularly in long and thin axons (Griffiths et al., 1998; Garbern et al., 2002; Edgar et al., 2004). Axonal spheroids, indicative of axonal damage, are observed by four months of age in germline knockouts of Plp (Griffiths et al., 1998), and four months following tamoxifen administration in inducible oligodendrocyte-specific knockouts (Luders et al., 2019). Axonal spheroids precede T-cell mediated infiltration though are coincident with astrogliosis and microglial activation (Luders et al., 2017, 2019). Similarly, mice lacking the Cnp1 gene have progressive axonal loss culminating in considerable axonal degeneration in the brain and shortened lifespan (LappeSiefke et al., 2003; Edgar et al., 2009). Comparable to the $P l p$ null mice, axon loss begins by about four months of age (LappeSiefke et al., 2003; Edgar et al., 2009). CNP is expressed in the inner, non-compact tongue of myelin (Braun et al., 1988; Trapp et al., 1988). Its knockout swells the inner tongue, but compact myelin thickness is normal and in early adulthood (P60) has equivalent numbers of myelinated axons (Edgar et al., 2009). So, what explains this apparent discrepancy - substantial demyelination and oligodendrocyte apoptosis throughout the CNS does not necessarily lead to axon degeneration, yet a number of single gene knockouts in oligodendrocytes do? In the case of toxin and genetic models of demyelination oligodendrocyte support is usually rapidly restored through oligodendrogenesis and remyelination with the bulk of remyelination occurring within two weeks in focal chemical models of demyelination (Duncan G. J. et al., 2017) and within two months in cuprizone demyelination (Sachs et al., 2014) and oligodendrocyte depletion (Traka et al., 2010). In contrast, within the Plp knockouts and Cnp1 null mice oligodendrocyte-axon interactions may be impaired throughout lifespan with axon loss taking at least four months to accrue. In both $P l p$ and Cnp knockout mice there is considerable evidence oligodendrocyte-axon interactions are impeded. $P l p$-null oligodendrocytes are outcompeted for axons by wildtype oligodendrocytes (Yool et al., 2001). This is especially true for small diameter axons, which are preferentially vulnerable in Plp null mice (Yool et al., 2001; Nave and Trapp, 2008). PLP may aide in the extension of processes and ensheathment of axons, which is necessary for the long-term stability of 
oligodendrocytes following differentiation (Hughes et al., 2018) and likely indicates a diminishment of oligodendrocyte-axon support in Plp null mice. Likewise, CNP is known to maintain the opening of cytoplasmic channels in myelin (Snaidero et al., 2017). If these channels are compromised in the Cnp1 null mice, oligodendrocyte support functions such as delivery of EVs (Fruhbeis et al., 2020) or lactate (Funfschilling et al., 2012; Lee et al., 2012) could be disrupted, leaving the myelinated portions of the axons stressed and vulnerable to loss. These studies indicate that, a long-term breakdown of normal oligodendroglial support, even if the myelin sheath is broadly maintained, can trigger axon loss.

\section{Does Remyelination Restore Neuronal Health and Function?}

With remyelinating therapies entering clinical trials (Green et al., 2017; Plemel et al., 2017; Stangel et al., 2017; Cadavid et al., 2019; Lubetzki et al., 2020b) it will be important to establish whether new oligodendrocytes are capable of supporting axonal integrity and function to a similar degree as those formed during development. Experimentally, there is evidence remyelinating oligodendrocytes may not confer the same level of support to neurons. In the cuprizone model of demyelination, axon loss can continue despite accomplished remyelination and cessation of cuprizone administration (Manrique-Hoyos et al., 2012). Remyelinated axons have higher mitochondrial content, suggesting that metabolic support may not be fully restored and a greater share of the energetic burden remains on the neuron (Zambonin et al., 2011). The myelin of adult-born oligodendrocytes is often thinner and internodes are typically shorter than those derived during development (Lasiene et al., 2009; Young et al., 2013; Duncan I. D. et al., 2017). This may contribute to the persistent motor deficits in genetic models of demyelination despite considerable levels of remyelination (Hartley et al., 2019). One approach to determine how effective remyelination is in protecting axons and restoring function has been to use the relative heterogeneity in remyelination in MS as a natural experiment. The level of axon damage between the subset of lesions capable of remyelination in MS - so called shadow plaques - is less than those that remain chronically demyelinated (Kornek et al., 2000; Kuhlmann et al., 2002). Likewise, to examine remyelination's role in recovery in MS, a recent study used positron emission tomography with a compound sensitive to myelin changes (Pittsburgh compound B) to characterize the extent of remyelination relative to disability (Bodini et al., 2016). Those with greater levels of remyelination had lower levels of disability (Bodini et al., 2016). It is important to note that these studies, while informative, represent only correlative evidence that remyelination is protective and restores function, not causal data. It remains possible that axons less-damaged during inflammatory demyelination are more receptive to remyelination in MS, which could also explain these associations.

Experimentally, only a few animal studies have attempted to determine if remyelination directly improves axonal health. This is in large part due to difficulty in decoupling inflammatory and degenerative processes from that of remyelination. To assess if a failure to remyelinate increases axonal damage, $\mathrm{X}$-irradiation was applied during cuprizone demyelination to deplete OPCs necessary for remyelination (Blakemore and Patterson, 1978; Irvine and Blakemore, 2007). Increased axonal damage, and fewer axons with highly phosphorylated neurofilaments were observed in the corpus callosum, both of which were rescued by transplantation of OPCs capable of remyelinating (Irvine and Blakemore, 2008). However, irradiation-induced changes in both astrogliosis and inflammation confounded whether remyelination failure is the specific causative agent that increased axonal damage. A more cell-specific gain of function approach was recently undertaken to determine the role of remyelination in axonal integrity by deleting the muscarinic receptor 1 from oligodendrocyte lineage cells (Mei et al., 2016). This resulted in more rapid remyelination and a greater number of neurofilament-positive axons following EAE, providing evidence of a neuroprotective role of remyelination. However, whether a failure to remyelinate, like that seen in MS lesions, triggers worsened axonal loss in the absence of autoimmune T-cell infiltration remains untested. Inducible cell-specific knockouts have been used to block de novo oligodendrogenesis in adulthood (McKenzie et al., 2014; Schneider et al., 2016; Xiao et al., 2016; Pan et al., 2020) and during repair (Duncan G. J. et al., 2017; Duncan et al., 2018) and may provide a selective approach to determine to what extent remyelination protects axons.

Remyelinated axons typically have shorter internodes and thinner myelin. This begs the question to what extent is remyelination capable of restoring conduction and behavior? Computer simulations indicate the sudden loss of a single myelinated internode along an axon may be sufficient to temporarily block conduction (Koles and Rasminsky, 1972; Waxman and Brill, 1978). In agreement with these simulations, conduction is highly diminished through focal lesions in the days after an injection of lysolecithin or ethidium bromide (Smith et al., 1979; Black et al., 1991). Endogenous remyelination was shown decades ago to improve conduction and increase the speed of propagation relative to demyelinated axons (Smith et al., 1979), a finding that identified remyelination as a truly regenerative process. Remyelination restores sodium channel clustering to the nodes and Kv1.1 and Kv1.2 channels to the juxtaparanode (Rasband et al., 1998; Coman et al., 2006). Nodal structure is critical for action potential propagation and its restoration likely helps reestablish conduction (ArancibiaCarcamo et al., 2017). Perhaps one of the most compelling instances by which remyelination promotes functional recovery is following high-dose radiation injury to rats. High doses of radiation depletes OPCs, induces oligodendrocyte death and causes demyelination (Kurita et al., 2001). Following brainwide demyelination induced by radiation, injection of human OPCs resulted in considerable remyelination and fully restored performance on a novel object recognition task or the rotarod depending if OPCs are injected into either the corpus callosum (for novel objection recognition) or cerebellum (for rotarod) (Piao et al., 2015). Remyelination is less critical for recovery in instances when axonal damage is high, or the spread of demyelination is low like traumatic injury to the spinal cord (Duncan et al., 2018). In such cases axons are likely able to 
restore conduction through small areas of demyelination (up to several millimeters in length) (Felts et al., 1997). Remyelination, therefore, seems more likely to propel recovery when the extent of demyelination is high, axon damage is low and the area of remyelination is large.

It is now clear that remyelination is broadly effective at improving nodal structure, conduction, and function at least relative to demyelinated axons. However, two recent publications (Bacmeister et al., 2020; Orthmann-Murphy et al., 2020) have made an interesting observation; the pattern of remyelination in gray matter diverges significantly from that of the initial myelination. Following cuprizone diet administration, the vast majority of myelinated internodes are lost in the upper cortical layers, where axons usually display an intermittent pattern of myelination (Bacmeister et al., 2020; Orthmann-Murphy et al., 2020). Following cessation of cuprizone administration, many axons were remyelinated at near-identical locations to the original internodes (Orthmann-Murphy et al., 2020). Axons which had a higher initial degree of myelination were more likely to be precisely remyelinated, suggesting the preference for myelinating particular neuronal populations can be maintained (Orthmann-Murphy et al., 2020). However, 32\% of denuded myelin sheaths were not replaced after 8 weeks, with a large number of new myelin sheaths instead being formed along previously unmyelinated axonal segments (Orthmann-Murphy et al., 2020). Even relatively small changes in de novo myelination by new oligodendrocytes have significant impacts on motor learning (McKenzie et al., 2014; Xiao et al., 2016), spatial learning (Steadman et al., 2019), and fear conditioning (Pan et al., 2020). This suggests that the altered pattern of cortical myelination seen following remyelination has the potential to disrupt higher-order brain function and synchrony between neuronal circuits. Interestingly, in the motor cortex forelimb reach training increased the proportion of demyelinated internodes that received myelin, suggesting selective activity paradigms may be necessary to reconstitute myelin patterns fully (Bacmeister et al., 2020). Training and rehabilitation might therefore need to be coupled with remyelinating therapeutics to not only increase the quantity but to target myelin to appropriate axons in demyelinating disease.

\section{NEURONAL ADAPTATIONS TO DEMYELINATION}

\section{Demyelination-Induces Changes to Axonal Ion Channels}

The disruption of oligodendrocyte-axon interactions during demyelination fundamentally reshapes the organization of excitatory domains along the axon. Breakdown of paranodal contact between the oligodendrocyte and the axon occurs at a very early stage during demyelination in both MS (Wolswijk and Balesar, 2003; Coman et al., 2006; Howell et al., 2006) and in EAE (Fu et al., 2011). The paranode acts as a diffusion barrier necessary to maintain the sodium channels at the node (Rios et al., 2003; Dupree et al., 2004; Zhang et al., 2020), and its loss instigates sodium channels to spread along the axolemma (Rios et al., 2003; Dupree et al., 2004). There is also increased expression of sodium channels (England et al., 1991) including the $\mathrm{N}_{\mathrm{av}} 1.2$ sodium channel following demyelination (Figure 2; Craner et al., 2003, 2004; Coman et al., 2006), which is normally restricted to unmyelinated axons (Caldwell et al., 2000; Boiko et al., 2001; Lubetzki et al., 2020a). The upregulation and increased expression of sodium channels likely has the benefit of restoring conduction through demyelinated segments stretching several millimeters (Felts et al., 1997), and might be crucial to recovery during the relapsing-remitting phase of MS and in rodent models of inflammatory demyelination (Trapp and Nave, 2008). However, demyelinated axons have notably slower conduction, and are more susceptible to generating ectopic action potentials (Smith and McDonald, 1982; Hamada and Kole, 2015). Further, heightened sodium channel expression results in increased axoplasmic $\mathrm{Na}^{+}$accumulation. Sodium must then be removed from the axon for repolarization via the increased operation of $\mathrm{Na}^{+} \mathrm{K}^{+}$ATPase, a highly energetic process (Trapp and Stys, 2009; Harris and Attwell, 2012). Changes to excitatory domains following demyelination may alleviate conduction block, but it culminates in slow, discordant, energy-intensive propagation of APs in the absence of oligodendrocyte myelination.

\section{Increased Mitochondrial Content in Demyelinated Axons}

It is perhaps not surprising that to support the increased energetic burden on the axon after demyelination, mitochondrial content is increased within demyelinated axons (Figure 2). An increase in the number of mitochondria was first detected in experimental demyelinated lesions (Mutsaers and Carroll, 1998; Sathornsumetee et al., 2000), then observed in MS (Sathornsumetee et al., 2000; Zambonin et al., 2011). Increased mitochondrial content and activation of respiratory chains is likely a generic change axons undergo when they lack myelin, as it is also observed in transgenic models like the compact myelin-deficient shiverer (Andrews et al., 2006; Joshi et al., 2015). There are both motile and stationary pools of mitochondria in the axon, and stationary mitochondria tend to accumulate in areas of high metabolic demand (Misgeld et al., 2007; Misgeld and Schwarz, 2017; Mandal and Drerup, 2019). A plausible signal for immobilization of mitochondria in demyelinated axons is the activity of $\mathrm{Na}^{+} \mathrm{K}^{+}$ATPase (Zhang et al., 2010; Ohno et al., 2011), linking metabolic requirements to mitochondrial trafficking. Indeed, demyelination increases the number of stationary mitochondria and this likely aids in meeting local metabolic burden of demyelinated axons (Kiryu-Seo et al., 2010). The axonal mitochondrial anchoring protein syntaphilin (Kang et al., 2008) increases in expression following demyelination and is necessary for the immobilization of mitochondria within the axon (Ohno et al., 2014). Following cuprizone demyelination, deletion of syntaphilin results in potentiated axon damage demonstrating the importance of mitochondrial anchoring to areas of high demand (Ohno et al., 2014). Energetic failure within the axon is the likely cause of increased damage in syntaphilin knockouts, as the blockade of sodium channels, and therefore 


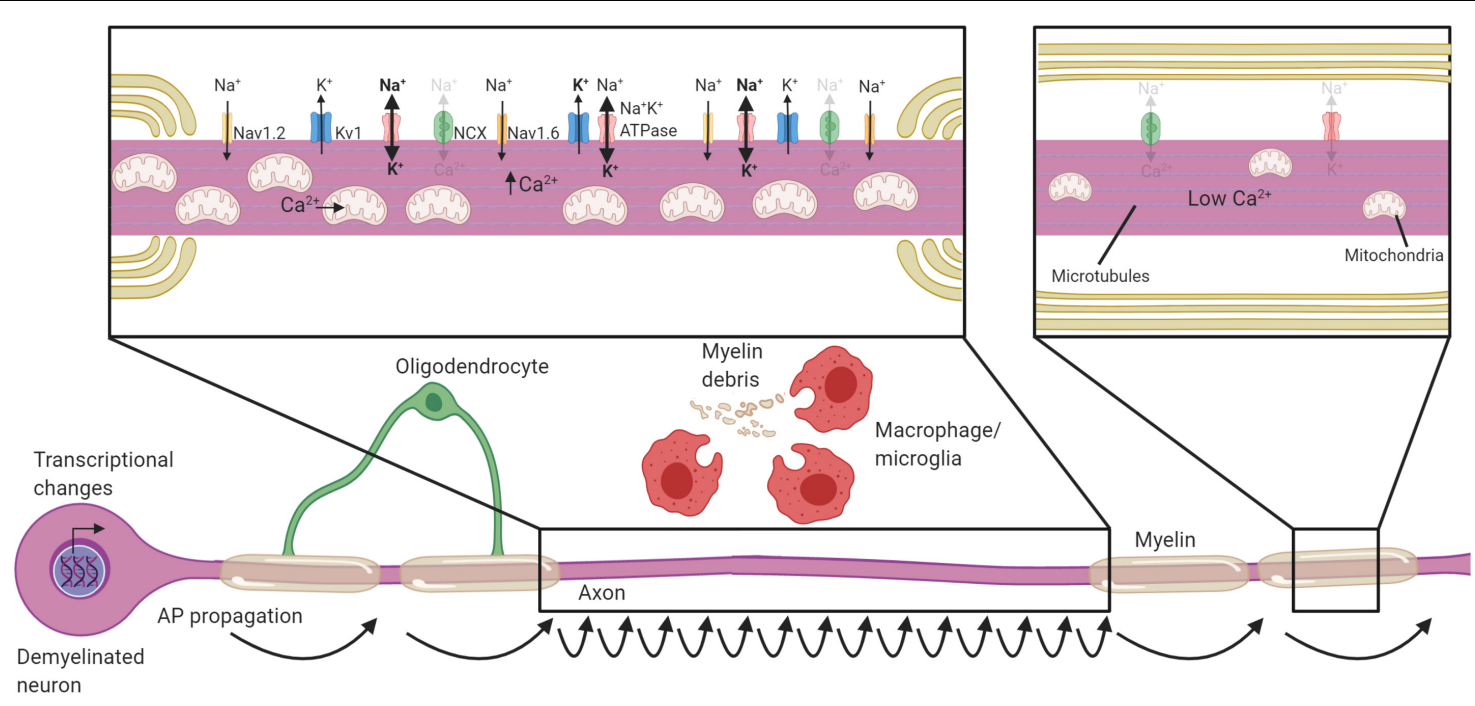

FIGURE 2 | Neuronal adaptations to acute demyelination. Schematic of a partially demyelinated neuron early after demyelination. Conduction is reestablished through the demyelinated segment by the increased expression of sodium channels along the axolemma, but it is notably slower. Demyelinated axons require greater $\mathrm{Na}^{+}$entry to depolarize the axon, necessitating increased activity of the $\mathrm{Na}^{+} \mathrm{K}^{+}$ATPase. Mitochondria increase in number and size within demyelinated axons to meet the higher demand for ATP and also uptake $\mathrm{Ca}^{2+}$. If $\mathrm{Na}^{+} \mathrm{K}^{+}$ATPase has sufficient ATP, the NCX is rarely activated in the reverse direction (faded arrows). Transcriptional changes occur within the neuron in response to demyelination and could be critical to these adaptions. Faded text and indicates low activity or levels, bolded text or thick arrows indicates increased levels following demyelination.

reduced activation of $\mathrm{Na}^{+} \mathrm{K}^{+}$ATPase, ameliorates the axonal damage (Ohno et al., 2014). Neuronal mitochondrogenesis and immobilization of mitochondria to sites of demyelination is therefore necessary to meet the increased energy burden placed on the axon following demyelination.

\section{Neuronal Transcriptional Responses to Demyelination}

Transcriptional changes often underlie differences in cellular function, and gene expression profiling has been undertaken in experimental chemical demyelinating lesions (Lovas et al., 2010) as well as in MS to examine neuronal gene changes (Dutta et al., 2007, 2011; Schirmer et al., 2019). Dutta et al. (2011) took advantage of the variable degree of demyelination within individual MS hippocampi to assess the influence of demyelination on gene expression. There is a significant reduction in the expression of genes regulating axonal transport and synaptic structure in the demyelinated hippocampi relative to myelinated hippocampi in MS and healthy controls (Dutta and Trapp, 2011). Subsequent studies have confirmed that synapse loss is a robust and early event in demyelinating disease (Jurgens et al., 2016; Werneburg et al., 2020) and axon transport is highly impaired by demyelination (Sorbara et al., 2014). There is also a shift toward inhibitory neurotransmission with genes involved in glutamatergic signaling downregulated and increased expression of genes involved in GABAergic neurotransmission following demyelination in the hippocampus (Dutta et al., 2011, 2013). These findings highlight how transcriptional changes can be used to identify physiological changes. One disadvantage of whole-tissue approaches is that they obscure which specific cell types expression changes are found in. Additionally, loss of specific types of cells may bias the differential expression data. Single-cell RNAseq offers an unbiased approach to examine the heterogeneity in gene expression between different cell types or can be used to determine if the cell-type constituents are changing. Single nuclei RNAseq was undertaken on the cortical and adjacent subcorticial white matter lesions from people with MS who did not receive immunomodulatory treatments (Schirmer et al., 2019). There is selective vulnerability of L2/L3 cortical neurons that were Cux2+, and these neurons demonstrated enhanced activation of cell-stress pathways and protein folding response (Schirmer et al., 2019). At this point, gene-expression studies comparing demyelinated versus myelinated neurons have uncovered wideranging expression changes in axonal transport, synaptic stability, inhibitory neurotransmission and the activation of cell stress pathways, which together reveals that virtually all aspects of their cellular function are altered following demyelination. Future studies should assess whether these transcriptional changes are induced by the inflammatory milieu of MS lesions or are a general consequence of demyelination. In addition, it will be important to functionally determine which of the transcriptional changes in demyelinated neurons are adaptive and which represent maladaptive or pathological changes.

\section{MECHANISMS OF AXONAL DEGENERATION FOLLOWING DEMYELINATION}

Neurons undergo swift changes in response to demyelination by altering their transcription, distribution of their excitatory 
domains, and energy metabolism. While these changes may be necessary for restoration of some level of conductance through demyelinated segments, the lack of oligodendrocytic support and increased energetic demands nevertheless leave neurons vulnerable to damage, particularly if not remyelinated over extended periods. Over the next several sections we will discuss potential mechanisms of axonal degeneration following demyelination. We will focus on how ion channel redistribution puts increased metabolic strain on the neuron, and when coupled with inflammatory mediators, oxidative damage, transport deficits and mitochondrial dysfunction, the axon is left with an energy deficit and ultimately is vulnerable to degeneration (Figure 3). We will also discuss the evidence that active "death signaling" pathways identified from studies of Wallerian degeneration may be involved in demyelinationassociated axonal degeneration.

\section{Axoplasmic Calcium Overload in Demyelinated Axons Triggers Axonal Degeneration}

Action potential propagation in axons without myelin requires greater influx of $\mathrm{Na}^{+}$to overcome the higher capacitance and subsequently change potential. To repolarize the demyelinated axon, increased activity of the $\mathrm{Na}^{+} \mathrm{K}^{+}$ATPase is needed to extrude the $\mathrm{Na}^{+}$(Trapp and Stys, 2009). The increased flux of $\mathrm{Na}^{+}$into demyelinated axons coincident with inflammation in MS has been hypothesized to cause an energy run-down within the axon, reminiscent of hypoxia (Trapp and Stys, 2009; Lassmann et al., 2012; Friese et al., 2014). In anoxic conditions, which greatly limit ATP production, $\mathrm{Na}^{+}$accumulation in the axon drives a reversal of the sodium-calcium exchanger (NCX) and a buildup of intracellular calcium ions $\left(\mathrm{Ca}^{2+}\right)$ (Stys et al., 1991, 1992). Calcium overload has long been identified as a general initiator of axonal degeneration, as calcium ionophores can directly drive axonal degeneration, while calcium chelators delay axonal degeneration following transection in vitro (Schlaepfer and Bunge, 1973; George et al., 1995). In EAE, chelation of extracellular calcium almost completely ameliorates axonal degeneration, at least over the short-term (Witte et al., 2019). The accumulation of calcium propels axonal degeneration by activating intra-axonal proteases like calpains, which break down cytoskeletal elements such as neurofilaments and microtubules (Kamakura et al., 1983; Billger et al., 1988), and execute axonal degeneration (Yang et al., 2013). Increased calpain activation is observed in both MS plaques and normal-appearing-white matter (NAWM; Shields et al., 1999), and inhibitors of calpains reduce axonal and neuronal damage in the context of EAE (Hassen et al., 2008; Smith et al., 2011). Demyelinated axons may, therefore, be particularly vulnerable to calcium overload and subsequent degeneration, especially when ATP production is limited and the NCX reverses (Figure 3).

\section{Entryways for Extracellular $\mathbf{C a}^{2+}$}

Identifying and inhibiting sources of axoplasmic calcium accumulation may be a protective strategy in demyelinating disease. Extracellular $\mathrm{Ca}^{2+}$ can reach concentrations as high as $1.5 \mathrm{mM}$ which is approximately $15,000 \times$ greater than the resting neuronal $\mathrm{Ca}^{2+}$ concentration of $\sim 100 \mathrm{nM}$ (Gleichmann and Mattson, 2011). This produces a strong gradient favoring movement of $\mathrm{Ca}^{2+}$ into the neuron. External influx of $\mathrm{Ca}^{2+}$ is typically regulated through voltage-gated calcium channels (VGCCs), glutamate receptors and non-selective cation channels (Stirling and Stys, 2010; Gleichmann and Mattson, 2011; Friese et al., 2014). During demyelination in both EAE and MS, in addition to L-type calcium channels which are typically found along axons, N-type calcium channels are upregulated and are associated with axonal swelling (Kornek et al., 2001; Gadjanski et al., 2009). Blockade of N or L-type calcium channels ameliorates EAE (Brand-Schieber and Werner, 2004; Gadjanski et al., 2009; Tokuhara et al., 2010; Ingwersen et al., 2018) and protects axons (Gadjanski et al., 2009; Ingwersen et al., 2018). There is also evidence that glutamate receptors may permit $\mathrm{Ca}^{2+}$ entry into demyelinated neurons. In MS, there is an elevation of glutamate in the brain (Srinivasan et al., 2006), potentially caused by release from dying neurons and glia, inflammatory cells (Pampliega et al., 2011) or via impaired uptake (Geurts et al., 2003; Cambron et al., 2012). When activated at prodigious levels glutamate receptors can result in $\mathrm{Ca}^{2+}$ entry and excitotoxicity. Accordingly, axonal degeneration is reduced in adoptive-transfer EAE when the AMPAR antagonist NBQX is administered (Pitt et al., 2000), and protects neurons in MBP-induced EAE in rats (Smith et al., 2000). Likewise, NMDAR antagonists like memantine, MK-801 and fullerene ABS-75 are axon-protective in EAE (Basso et al., 2008; Farjam et al., 2014; Levite, 2017). This demonstrates that glutamate or VGCC blockade can be effective at alleviating axon loss following inflammatory demyelination. A caveat is that glutamate and VGCCs have potent effects on inflammatory activation in EAE (Smith et al., 2000; Basso et al., 2008; Fallarino et al., 2010; Tokuhara et al., 2010; Sulkowski et al., 2013; Fazio et al., 2014; Ingwersen et al., 2018) making it difficult to ascertain how much of the neuroprotection is derived by a direct alleviation of calcium overload in the axon relative to immunomodulation. Administration of VGCC inhibitors during EAE does not diminish $\mathrm{Ca}^{2+}$ levels in the axon when examined using a genetic indicator of intracellular calcium, arguing against a direct axonal-protective effect (Witte et al., 2019). Likewise, application of glutamate agonists are not sufficient to drive axonal $\mathrm{Ca}^{2+}$ in the spinal cord axons (Witte et al., 2019). This argues that immune modulation may be responsible for VGCC and glutamate-mediated axonal protection rather than via direct modulation of $\mathrm{Ca}^{2+}$ levels in the axon. Interestingly, axons in EAE are permeable to extracellular molecules of up to $10 \mathrm{kDa}$ in size indicative of small, non-specific ruptures $(<10 \mathrm{~nm})$ in the axoplasmic membrane. The cause of these "nano-ruptures" in the membrane is unclear but are associated with inflammation, and inflammatory cells are known to secrete membrane rupturing proteins like perforins and complement (Zhao et al., 2018). This presents a novel axis by which $\mathrm{Ca}^{2+}$ can enter the axon - through direct damage to the membrane. Interestingly, myelinated axons had reduced permeability of $10 \mathrm{kDa}$ molecules suggestive of fewer nano-ruptures (Witte et al., 2019). A shielding effect of myelin on the axon from immune mediators may be another mechanism by which oligodendrocytes protect axons. Whether nano-ruptures 


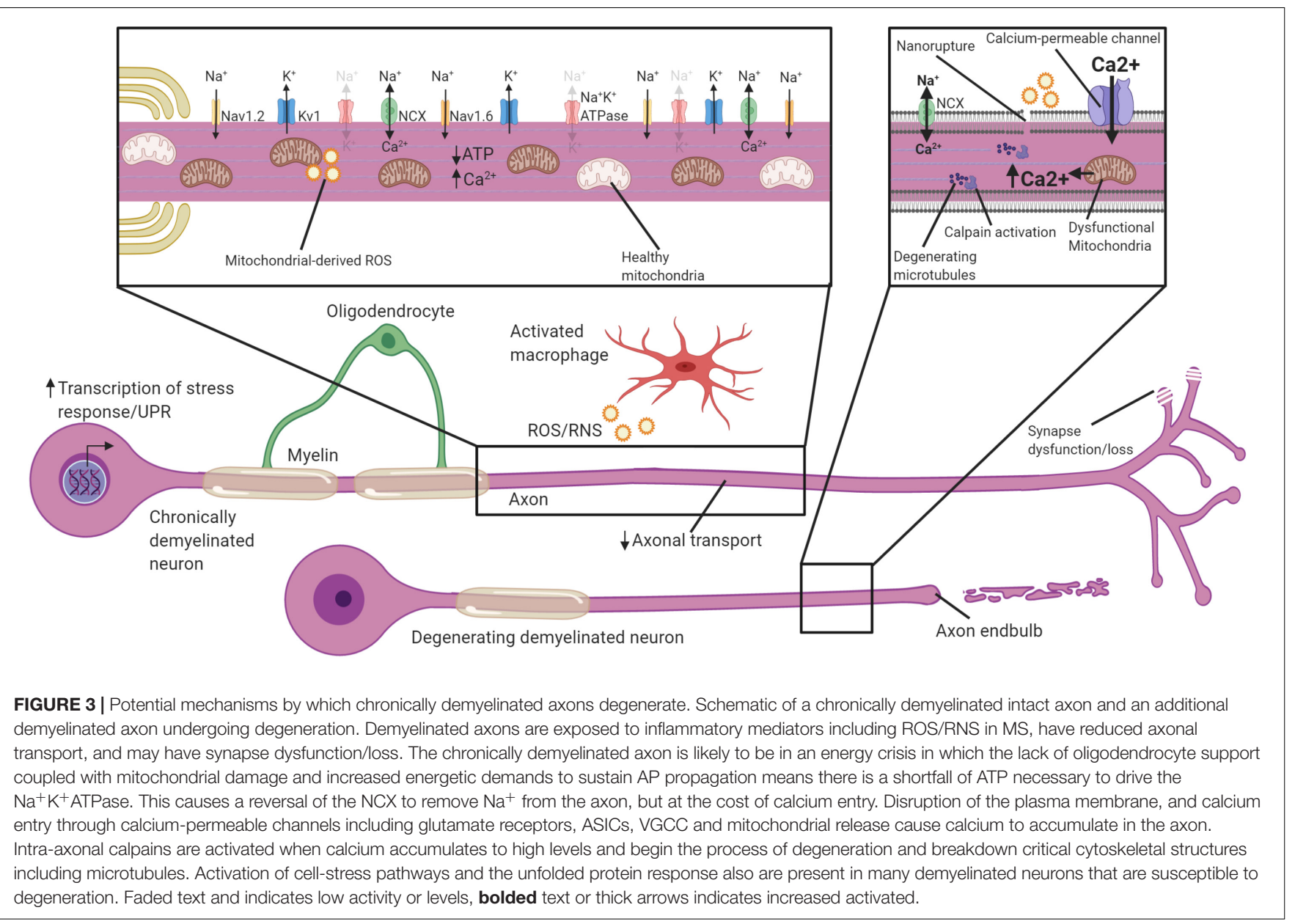

occur or constitute a major source of intra-axonal calcium in the absence of auto-immunity would be interesting to test in chemical or genetic models of demyelination.

\section{Mitochondria Contribute to Axonal Calcium Overload}

There are two main organelles which store calcium; the endoplasmic reticulum (ER) and mitochondria. Release of these internal sources of $\mathrm{Ca}^{2+}$ could contribute to calcium overloading in demyelinating disease. During excitotoxic injury (Ouardouz et al., 2009), axotomy (Stirling et al., 2014; Villegas et al., 2014), or oxygen-glucose deprivation (Ouardouz et al., 2003), ER $\mathrm{Ca}^{2+}$ release contributes to axoplasmic calcium overloading and subsequent degeneration. However, the depletion of endoplasmic stores with caffeine does not induce axoplasmic $\mathrm{Ca}^{2+}$ rises in axons in EAE (Witte et al., 2019), and to our knowledge there is no direct evidence demonstrating axoplasmic $\mathrm{Ca}^{2+}$ contributes to axonal degeneration during demyelination. However, mitochondria likely do contribute to axoplasmic $\mathrm{Ca}^{2+}$ dynamics. The mitochondria calcium uniporter (MCU) is the primary $\mathrm{Ca}^{2+}$ transporter involved with buffering calcium in mitochondria. The MCU increases uptake during times of high cytoplasmic $\mathrm{Ca}^{2+}$ and low ATP/ADP ratio
(Igbavboa and Pfeiffer, 1988; Litsky and Pfeiffer, 1997; Baughman et al., 2011; De Stefani et al., 2011; Gleichmann and Mattson, 2011). $\mathrm{Ca}^{2+}$ uptake into the mitochondria increases ATP synthesis by activating dehydrogenases that make reducing equivalents, which drive complex I activity (Denton et al., 1972; Nichols et al., 2017). Therefore, $\mathrm{Ca}^{2+}$ influx into mitochondria may serve two important roles: to reduce cytoplasmic calcium accumulation and to increase ATP production. Deletion of the MCU from neurons following induction of $\mathrm{MOG}_{35-55} \mathrm{EAE}$, exacerbates EAE severity, reduces ATP content in the spinal cord and increases axonal damage (Holman et al., 2020). More T-cells and myeloid cells are found in mice with neuronspecific deletion of MCU (Holman et al., 2020), indicating that heightened inflammatory activity can be secondary to potentiated neuronal damage. If calcium buffering in mitochondria is critical for axonal health, increased efflux of $\mathrm{Ca}^{2+}$ from the mitochondria should leave axons vulnerable to degeneration in demyelinating disease. The mitochondrial permeability transition pore (MPTP) can drive the efflux of calcium from the mitochondria, and is regulated by cyclophilin D (Connern and Halestrap, 1996; Nicolli et al., 1996). The absence of cyclophilin D makes the MPTP threshold for opening higher and would be predicted to make the axon more resistant to damage during demyelination. Germline cyclophilin D knockout mice had less damage 
and reduced EAE severity (Forte et al., 2007). Inflammatory infiltration of T-cells or monocytes is not inhibited, suggestive of a direct effect on neuronal health (Forte et al., 2007). A pharmacological inhibitor of the MPTP also reduced EAE severity and decreased axonal damage (Warne et al., 2016). Taken together, mitochondrial calcium uptake has an important role in reducing neuronal damage following demyelination, likely by ameliorating calcium rise within the axoplasmic compartment and by increasing ATP production.

\section{Sodium Channel Activation Is Associated With Axonal Degeneration Following Demyelination}

The increased expression of sodium channels along demyelinated axons raises their metabolic demand and places increased energetic stress on the axon. In both EAE and in MS lesions, $\mathrm{Na}_{\mathrm{V}} 1.6$ channels colocalize with the NCX (Craner et al., 2003, 2004), which under conditions of energetic stress imports $\mathrm{Ca}^{2+}$ in order to extrude $\mathrm{Na}^{+}$(Figure 3; Stys et al., 1991, 1992). This posits a mechanism by which $\mathrm{Na}^{+}$accumulation during an energetic rundown can directly contribute to $\mathrm{Ca}^{2+}$ buildup. Axons with $\mathrm{N}_{\mathrm{av}} 1.6$ and NCX colocalization are much more prone to $\beta$ APP expression in MS, a marker of transport deficit and axonal damage (Craner et al., 2003, 2004). Broad pharmacological inhibitors of sodium channels during EAE reduce axonal damage and motor impairment (Lo et al., 2003; Bechtold et al., 2004, 2006; Black and Waxman, 2008; Morsali et al., 2013; Al-Izki et al., 2014). However, from these studies it was unclear if sodium blockade diminished axonal damage by acting directly on the axon or via its known role in diminishing microglia/macrophage infiltration and activation within the CNS (Craner et al., 2005; Black et al., 2009; Morsali et al., 2013). Cell-specific targeting of voltage-gated sodium channels in neurons demonstrates that sodium channels can act directly on neurons to drive their damage in EAE. Using adeno-associated virus (AAV) deletion of $\mathrm{Na}_{\mathrm{v}} 1.6$ in RGCs following EAE, greater preservation of axons in the optic nerve is observed as well as reduced neuronal loss (Alrashdi et al., 2019). Unfortunately, clinical trials of sodium channel blockers have been less promising with early clinical trials in those with SPMS using lamotrigine having found diminished brain volume relative to placebo over the first year before stabilizing (Kapoor et al., 2010; Hayton et al., 2012). Brain volume measures can be confounded by inflammatory infiltrate and edema, which is likely reduced by sodium channel blockade and could have contributed to this decline in brain volume before stabilization (Franklin et al., 2012). A recent clinical trial using optical coherence tomography (OCT) to measure neurodegeneration within the retinal nerve fiber layer (RNFL) in those with optic neuritis found that treatment with the sodium channel blocker phenytoin resulted in a $30 \%$ reduction in the thinning of the RNFL and increased macular volume after six months (Raftopoulos et al., 2016). This study highlights that voltage-gated sodium blockade may provide some level of neuroprotection, at least during RRMS. However, it is still unclear the precise mechanism(s) by which sodium blockade confers axon protection and if it contributes to calcium overloading following demyelination.

\section{Axon Transport Deficits Following Demyelination Impair Energy Production in the Axon Leaving It Vulnerable to Degeneration}

The axon represents a logistical challenge unique amongst any cell-type; mRNA, proteins and organelles produced in the soma must be trafficked for vast distances. For example, corticospinal neurons can have an axon over $1 \mathrm{~m}$ long, exceeding the size of its soma by 50,000 times. Mitochondria require nuclear genes in addition to their own genome for proper function, and mitochondrial biogenesis mostly occurs in the soma (Calvo et al., 2016). Mitochondria are then trafficked to meet local energy requirements along the axon (Misgeld and Schwarz, 2017; Campbell et al., 2019). This logistical bottleneck along with proximity to inflammation in the axon, can make mitochondria highly sensitive to damage and dysfunction in demyelinating lesions, which presents an axis of vulnerability especially in long axons.

In EAE, both anterograde and retrograde deficits in mitochondrial transport are detected, with anterograde transport more adversely affected (Sorbara et al., 2014). Transport deficits precede axonal blebbing and outright degeneration (Sorbara et al., 2014). Inflammatory mediators like reactive oxygen species (ROS) and reactive nitrogen species (RNS) directly impair transport of mitochondria following EAE, evident by the restoration of transport when ROS/RNS scavengers are administered (Sorbara et al., 2014). Another potential inhibitor of axonal transport in demyelinated axons includes excitotoxicity from glutamate (or TNF $\alpha$ exposure), which causes a calciumdependent relocalization of histone deacetylase 1 (HDAC1) from the nucleus to the axon (Kim et al., 2010). Axonal HDAC1 interacts with the kinesin family of motor proteins where it hinders their interaction with cargo such as mitochondria to diminish their transport (Kim et al., 2010). Downregulation of $\mathrm{HDACl}$ or preventing its translocation from the nucleus reduces axonal damage following glutamate exposure (Kim et al., 2010).

If reduced transport of mitochondria to the axon is associated with axonal damage can increasing transport be protective? Overexpression of the protein Miro1, which tethers mitochondria to their motor adaptor complex, or mitochondrial biogenesis peroxisome proliferator activated receptor gamma coactivator 1-alpha (PGC1- $\alpha)$ are effective at increasing anterograde transport and reducing axonal damage following demyelination of cerebellar slice cultures (Licht-Mayer et al., 2020). Considering that kinesins require ATP hydrolysis to move cargoes such as mitochondria through the axons, a positive feedback loop may occur where the axon does not have the energy to effectively translocate the mitochondria to meet localized energy production, which in turn further impairs energy production at distal sites. This may explain why mitochondria content falls in distal component of the axon in chronic MS and EAE (Dutta et al., 2006; Sorbara et al., 2014). A failure of energy production at the synapses, which require considerable energy 
for neurotransmission (Lennie, 2003), may contribute to their loss/dysfunction in MS and demyelinating models (Jurgens et al., 2016; Werneburg et al., 2020).

\section{Mitochondrial Damage and Dysfunction Following Demyelination}

Microglia/macrophages closely appose axons during inflammatory demyelination (Nikic et al., 2011), and produce ROS and RNS which can impair and damage mitochondria. The best studied reactive species in the context of demyelination is nitric oxide (NO). NO is not inherently cytotoxic and has many important physiological roles including mediating vasodilation. However, when combined with superoxide it forms the toxic peroxynitrate which oxidizes tyrosine residues and damages proteins (Pacher et al., 2007). Importantly, NO also binds the ferrous heme of cytochrome c oxidase (mitochondrial complex IV) drastically reducing mitochondrial respiration (Brown and Cooper, 1994; Cleeter et al., 1994). Inducible nitric oxide synthase (iNOS) expression and nitrotyrosine residues are found in active MS lesions and the active edge of chronic MS lesions (Bo et al., 1994; Cross et al., 1996; Oleszak et al., 1998; Lu et al., 2000; Liu et al., 2001; Marik et al., 2007). Early active lesions in MS have selectively reduced activity of complex IV (Mahad et al., 2008), whose expression and functionality can be directly targeted by NO (Brown and Cooper, 1994; Cleeter et al., 1994; Wei et al., 2002). NO exposure blocks conduction in demyelinated axons (Redford et al., 1997) and results in axonal degeneration during high frequency stimulation (Smith et al., 2001; Kapoor et al., 2003). The selective vulnerability of axons during high frequency stimulation suggests that NO disrupts energy production, which leaves axons under intense energetic burden to remove excess sodium, which may culminate in the reversal of the NCX. In agreement with this hypothesis, sodium channel blockers and NCX inhibitors were shown to have a protective effect and ameliorate axonal degeneration following $\mathrm{NO}$ administration (Kapoor et al., 2003). Live-imaging studies during EAE provide further evidence that inflammation triggers mitochondrial dysfunction during demyelination, in part through a NOmediated mechanism. Fluorescently labeled mitochondria along with potentiometric dyes were used to determine that with the onset of inflammation there is a collapse of axonal mitochondrial membrane potential, indicative of mitochondrial dysfunction (Sadeghian et al., 2016). Both hydrogen peroxide and NO treatment to spinal axons induced swelling of mitochondria within axons (Nikic et al., 2011), and treatment with ROS/RNS species scavengers attenuates mitochondrial swelling and axonal degeneration during EAE (Nikic et al., 2011). However, it was not determined if NO specifically is causative in impairing mitochondrial respiration in these studies of EAE. It also remains unclear if mitochondrial dysfunction induced by ROS/RNS plays a major role during the chronic phases of MS when acute demyelinating lesions become rare or in demyelinating diseases that do not have considerable inflammatory infiltrate, such as inherited leukodystrophies.

Mitochondria damage continues to accrue during chronic demyelination. Mitochondrial DNA (mtDNA) lacks protective histones and some DNA repair enzymes making it vulnerable to damage (Yakes and Van Houten, 1997; Calvo et al., 2016; van den Berg et al., 2017) and oxidative damage to mtDNA is detected in MS (Haider et al., 2011). With disease chronicity there is an accumulation of cortical neurons with deficient Complex IV respiration, which is encoded in part by mtDNA (Dutta et al., 2006; Zambonin et al., 2010; Campbell et al., 2011), whereas nuclear-encoded Complex II respiration is often intact, a common characteristic of mitochondrial diseases (DiMauro and Schon, 2003). Dissecting these respiratory deficient neurons specifically, some studies found they had a high rate of mtDNA deletions, which may be further amplified over time via clonal expansion (Campbell et al., 2012). Mitochondrial injury and respiratory chain dysfunction lead to the liberation of more electrons which can then subsequently react with oxygen and induce more ROS-mediated damage. This constitutes a positive feedback loop that can increasingly imperil energy production in the neuron. Damaged mitochondria are removed by mitophagy, a process that requires fusion of the mitochondrial membrane with the lysosome in the soma or potentially to some extent within the axon (Misgeld and Schwarz, 2017). Expression of synaptophilin, necessary to anchor mitochondria to demyelinated internodes (Ohno et al., 2014), also impairs their transport and renders mitochondria unable to be effectively degraded following chronic stress (Lin et al., 2017). In this sense, increased energy demand during chronic demyelination coincides with accumulating damage and decreased elimination of dysfunctional mitochondria. Unfortunately, the long-term oxidative damage to mitochondria and failure of the respiratory chain observed in progressive MS is not typically detected in rodent models (Schuh et al., 2014), making it challenging to use these experimental models to assess to what extent mitochondrial dysfunction drives degeneration.

\section{Are Intra-Axonal Signaling Cascades Important for Wallerian Degeneration Involved in Axonal Degeneration in Demyelinating Disease?}

The term Wallerian degeneration is used to describe the process by which the distal axon degenerates following injury along with the subsequent activation of glia (Waller, 1851; Gaudet et al., 2011; Wang et al., 2012). The discovery of a spontaneous mutant, the slow-Wallerian degeneration mouse $\left(W l d^{s}\right)$ that greatly delays axonal degeneration following transection (Lunn et al., 1989), has permitted a detailed understanding of the molecular mechanisms underlying Wallerian degeneration. A comprehensive description of theses mechanisms is beyond the scope of this review and has been recently covered in a number of excellent reviews (Freeman, 2014; Gerdts et al., 2016; Coleman and Hoke, 2020). However, many of the proteins identified contribute to axon and neuron loss in neurodegenerative diseases like ALS and $\mathrm{AD}$, as well as potentially in demyelinating diseases (Coleman and Hoke, 2020). Indeed, there is considerable evidence of Wallerian-like degeneration following demyelination in MS. Diffuse axonal damage and degeneration is observed distal to lesions throughout the NAWM early during the 
disease (Kornek et al., 2000; Filippi et al., 2003) consistent with transected distal axons in acute lesions undergoing Wallerian degeneration. Additionally, Neuropeptide Y1-receptor, a marker for transected axons undergoing Wallerian degeneration (Pesini et al., 1999), is detected in MS lesions and NAWM (Dziedzic et al., 2010; Singh et al., 2017). To determine if Wallerian degeneration has a functional role in disease presentation or axonal degeneration in EAE, Chitnis et al. (2007) induced EAE in $W l d^{s}$ mice. $W l d^{s}$ mice initially have reduced axonal degeneration and disease severity, but disease severity worsens overtime to be no different than controls (Chitnis et al., 2007). While the authors did not examine axonal degeneration at that later time point, a recent study examining the knockout of Sarm1, a downstream effector necessary for Wallerian degeneration (Osterloh et al., 2012), in EAE found diminished axon damage early but no long-term benefit on axonal health (Viar et al., 2020). Taken together, Wallerian degeneration contributes to axonal loss in MS and EAE, but $W l d^{s}$ and related proteins do not seem to confer long-term axonal protection against immunemediated demyelination.

The failure to deliver a critical survival factor following axotomy to the axon from the soma was proposed decades ago by Lubinska to be the trigger for Wallerian degeneration (Lubinska, 1982). In 2010, such a protein was identified (Gilley and Coleman, 2010). Nicotinamide mononucleotide adenylyltransferase 2 (NMNAT2), is a highly labile protein necessary for the maintenance of the axon that is anterogradely transported and rapidly degraded following axotomy (Gilley and Coleman, 2010). NMNAT2 regulates NAD biosynthesis, which is critical for redox reactions necessary to maintain mitochondrial respiration and ATP production. This suggests that proteins critical to inhibiting Wallerian degeneration intersect with, and are necessary for, energy homeostasis. Given that axonal energy deficiency is linked to axon loss in demyelinating disease (Trapp and Stys, 2009), it is plausible that bolstering NMNAT or NAD levels may be an effective approach to enhance axon protection following demyelination. NAD levels decline during EAE and supplying NAD or its precursors diminishes demyelination and axonal damage (Kaneko et al., 2006; Tullius et al., 2014). However, $\mathrm{NAD}$ is also a major immune-regulatory molecule and can modulate T-cell infiltration and differentiation following EAE (Kaneko et al., 2006; Tullius et al., 2014). Future work should determine if NAD acts directly on axons following demyelination, or if axonal protective effects are primarily through immunemodulation. Either way, the finding that NAD protects against axonal degeneration in EAE is intriguing and potentially offers a new axis for treatments that protect against axonal degeneration.

Studies of Wallerian degeneration have also revealed active 'death signaling' within the axon is necessary for axonal degeneration (Wang et al., 2012; Llobet Rosell and Neukomm, 2019). Inhibition of mitogen-associated kinases (MAPKs), especially dual leucine zipper kinase (DLK), protect axons following axotomy, and likely constitutes such a death signal (Miller et al., 2009). Interestingly, MAPK signaling intersects with NAD biosynthesis as activated MAPK signaling promotes NMNAT2 turnover (Walker et al., 2017). Likewise, the downregulation of DLK along with the related leucine zipper kinase (LZK) preserves NMNAT2 levels and neurites in vitro (Summers et al., 2018). At this time, there is no direct evidence that DLK is regulated or MAPKs are phosphorylated following demyelination, however there is considerable reason to believe these pathways may be involved. Axonal transport is rapidly affected by inflammatory demyelination (Sorbara et al., 2014) and DLK inhibition protects against insults to fast axonal transport imparted by vincristine (Miller et al., 2009; Summers et al., 2018). Additionally, when mitochondria respiration is inhibited (such as by sub-lethal doses of the ATPase inhibitor oligomycin) NMNAT2 levels fall and activation of DLK signaling drives axonal degeneration (Summers et al., 2020). If MAPK signaling is activated following demyelination, it may serve as druggable target with overlap to other neurodegenerative disorders like ALS and AD where targeting of DLK reduces neurodegeneration in rodent models (Le Pichon et al., 2017).

\section{CONCLUSION AND FUTURE PERSPECTIVES}

The interaction between the oligodendrocyte and axon is critical for axonal structure and function, which is necessary for the rapid and timely propagation of action potentials throughout the CNS. The loss of myelin and oligodendrocytes fundamentally alters the neuron. Neurons restructure their excitatory domains, increase their mitochondrial content, and undergo significant transcriptional changes in response to demyelination. While these adaptations may allow some degree of functional restoration and conductance, it ultimately leaves the axon vulnerable to damage. Demyelinated axons that lack oligodendrocyte support are susceptible to energetic failure and the accumulation of intracellular calcium, which drives subsequent degeneration.

While there has been much progress in recent years in understanding how oligodendrocytes support axons in health and disease, a number of critical questions remain. Given numerous clinical trials are beginning with the aim of improving remyelination, it will be crucial to determine whether remyelinating oligodendrocytes provide long-term support of axonal health and how they differ from those produced during development. Are core functions of oligodendrocytes such as potassium buffering and metabolic support fully restored following remyelination? Already, single-cell RNA sequencing are providing clues and finding distinctions between oligodendrocytes formed in development and those during remyelination (Falcao et al., 2018; Jakel et al., 2019). Likewise new tools available to neuroscientists will be helpful in unraveling how demyelinated neurons degenerate. While it is clear that calcium overload drives axonal degeneration during acute inflammatory demyelination (Witte et al., 2019), determining the extent to which energetic rundown and calcium accumulation drives degeneration in chronically demyelinated axons is of pressing concern. Advances in two-photon live-imaging along with genetically encoded sensors for ATP, calcium and other molecules in demyelinating axons will be crucial tools for answering this question and determining the mechanisms by which calcium accumulates and mitochondria are damaged 
(Trevisiol et al., 2017; Looser et al., 2018). Likewise, genetic models of demyelination, which offer cell-specificity and the potential to impair subsequent remyelination (Duncan G. J. et al., 2017), will be important for delineating how neurons respond to demyelination, which changes are protective, and for identifying neuroprotective targets. The breakdown of oligodendrocyte-axon interactions is seen in a variety of neurological disorders beyond the classical demyelinating diseases; a further understanding of the molecular mechanisms by which demyelinated axons degenerate will likely offer novel therapeutic insights to alleviate decline in these pathologies.

\section{AUTHOR CONTRIBUTIONS}

GD and BE contributed to the conception and design of the review. GD prepared the figures. All authors contributed to the writing, editing, and approval of the submitted manuscript.

\section{REFERENCES}

Agarwal, D., Sandor, C., Volpato, V., Caffrey, T. M., Monzon-Sandoval, J., Bowden, R., et al. (2020). A single-cell atlas of the human substantia nigra reveals cell-specific pathways associated with neurological disorders. Nat. Commun. 11:4183. doi: 10.1038/s41467-020-17876-0

Aggarwal, S., Yurlova, L., and Simons, M. (2011). Central nervous system myelin: structure, synthesis and assembly. Trends Cell Biol. 21, 585-593. doi: 10.1016/j. tcb.2011.06.004

Aharoni, R., Vainshtein, A., Stock, A., Eilam, R., From, R., Shinder, V., et al. (2011). Distinct pathological patterns in relapsing-remitting and chronic models of experimental autoimmune enchephalomyelitis and the neuroprotective effect of glatiramer acetate. J. Autoimmun. 37, 228-241. doi: 10.1016/j.jaut.2011.06.003

Al-Izki, S., Pryce, G., Hankey, D. J., Lidster, K., Von Kutzleben, S. M., Browne, L., et al. (2014). Lesional-targeting of neuroprotection to the inflammatory penumbra in experimental multiple sclerosis. Brain 137, 92-108. doi: /10.1093/ brain/awt324

Alrashdi, B., Dawod, B., Schampel, A., Tacke, S., Kuerten, S., Marshall, J. S., et al. (2019). Nav1.6 promotes inflammation and neuronal degeneration in a mouse model of multiple sclerosis. J. Neuroinflammation 16:215. doi: 10.1186/s12974019-1622-1

Anderson, T. J., Schneider, A., Barrie, J. A., Klugmann, M., Mcculloch, M. C., Kirkham, D., et al. (1998). Late-onset neurodegeneration in mice with increased dosage of the proteolipid protein gene. J. Comp. Neurol. 394, 506-519. doi: 10.1002/(SICI)1096-9861(19980518)394:4<506::AID-CNE8>3.0.CO;2-5

Andrews, H., White, K., Thomson, C., Edgar, J., Bates, D., Griffiths, I., et al. (2006). Increased axonal mitochondrial activity as an adaptation to myelin deficiency in the Shiverer mouse. J. Neurosci. Res. 83, 1533-1539. doi: 10.1002/jnr. 20842

Arancibia-Carcamo, I. L., Ford, M. C., Cossell, L., Ishida, K., Tohyama, K., and Attwell, D. (2017). Node of Ranvier length as a potential regulator of myelinated axon conduction speed. eLife 6:e23329. doi: 10.7554/eLife.23329

Arroyo, E. J., Xu, T., Grinspan, J., Lambert, S., Levinson, S. R., Brophy, P. J., et al. (2002). Genetic dysmyelination alters the molecular architecture of the nodal region. J. Neurosci. 22, 1726-1737. doi: 10.1523/JNEUROSCI.22-0501726.2002

Bacmeister, C. M., Barr, H. J., Mcclain, C. R., Thornton, M. A., Nettles, D., Welle, C. G., et al. (2020). Motor learning promotes remyelination via new and surviving oligodendrocytes. Nat. Neurosci. 23, 819-831. doi: 10.1038/s41593020-0637-3

Bai, C. B., Sun, S., Roholt, A., Benson, E., Edberg, D., Medicetty, S., et al. (2016). A mouse model for testing remyelinating therapies. Exp. Neurol. 283, 330-340. doi: 10.1016/j.expneurol.2016.06.033

\section{FUNDING}

This work was supported by grants from the NIH/National Institute of Neurological Disorders and Stroke (R21NS111211), Race to Erase MS and the National Multiple Sclerosis Society (RG-2001-35775). GD was supported by a National Multiple Sclerosis Society fellowship (FG-1808-32238) and by a gift from Caron and Larry Ogg. TS was supported by the U.S. Department of Veterans Affairs as an Advanced Fellow in Multiple Sclerosis (370834). BE was supported by an endowment from the Warren family.

\section{ACKNOWLEDGMENTS}

We would like to thank Peggy Assinck, Brett J. Hilton, and Jason R. Plemel for their insightful discussions and critical feedback on this manuscript. Figures were created with BioRender.com.

Basso, A. S., Frenkel, D., Quintana, F. J., Costa-Pinto, F. A., Petrovic-Stojkovic, S., Puckett, L., et al. (2008). Reversal of axonal loss and disability in a mouse model of progressive multiple sclerosis. J. Clin. Invest. 118, 1532-1543. doi: 10.1172/JCI33464

Battefeld, A., Klooster, J., and Kole, M. H. (2016). Myelinating satellite oligodendrocytes are integrated in a glial syncytium constraining neuronal high-frequency activity. Nat. Commun. 7:11298. doi: 10.1038/ncomms11298

Baughman, J. M., Perocchi, F., Girgis, H. S., Plovanich, M., Belcher-Timme, C. A., Sancak, Y., et al. (2011). Integrative genomics identifies MCU as an essential component of the mitochondrial calcium uniporter. Nature 476, 341-345. doi: 10.1038/nature10234

Bechtold, D. A., Kapoor, R., and Smith, K. J. (2004). Axonal protection using flecainide in experimental autoimmune encephalomyelitis. Ann. Neurol. 55, 607-616. doi: 10.1002/ana.20045

Bechtold, D. A., Miller, S. J., Dawson, A. C., Sun, Y., Kapoor, R., Berry, D., et al. (2006). Axonal protection achieved in a model of multiple sclerosis using lamotrigine. J. Neurol. 253, 1542-1551. doi: 10.1007/s00415-006-0204-1

Berard, J. L., Wolak, K., Fournier, S., and David, S. (2010). Characterization of relapsing-remitting and chronic forms of experimental autoimmune encephalomyelitis in C57BL/6 mice. Glia 58, 434-445. doi: 10.1002/glia. 20935

Billger, M., Wallin, M., and Karlsson, J. O. (1988). Proteolysis of tubulin and microtubule-associated proteins 1 and 2 by calpain I and II. Difference in sensitivity of assembled and disassembled microtubules. Cell Calcium 9, 33-44. doi: 10.1016/0143-4160(88)90036-X

Bitsch, A., Schuchardt, J., Bunkowski, S., Kuhlmann, T., and Bruck, W. (2000). Acute axonal injury in multiple sclerosis. Correlation with demyelination and inflammation. Brain 123(Pt 6), 1174-1183. doi: 10.1093/brain/123.6.1174

Bjartmar, C., Kidd, G., Mork, S., Rudick, R., and Trapp, B. D. (2000). Neurological disability correlates with spinal cord axonal loss and reduced $\mathrm{N}$-acetyl aspartate in chronic multiple sclerosis patients. Ann. Neurol. 48, 893-901. doi: 10.1002/ 1531-8249(200012)48:6<893::AID-ANA10>3.0.CO;2-B

Black, J. A., Felts, P., Smith, K. J., Kocsis, J. D., and Waxman, S. G. (1991). Distribution of sodium channels in chronically demyelinated spinal cord axons: immuno-ultrastructural localization and electrophysiological observations. Brain Res. 544, 59-70. doi: 10.1016/0006-8993(91)90885-Y

Black, J. A., Liu, S., and Waxman, S. G. (2009). Sodium channel activity modulates multiple functions in microglia. Glia 57, 1072-1081. doi: 10.1002/glia.20830

Black, J. A., and Waxman, S. G. (2008). Phenytoin protects central axons in experimental autoimmune encephalomyelitis. J. Neurol. Sci. 274, 57-63. doi: 10.1016/j.jns.2008.04.001

Blakemore, W. F., and Patterson, R. C. (1978). Suppression of remyelination in the CNS by X-irradiation. Acta Neuropathol. 42, 105-113. doi: 10.1007/BF00690975 
Bo, L., Dawson, T. M., Wesselingh, S., Mork, S., Choi, S., Kong, P. A., et al. (1994). Induction of nitric oxide synthase in demyelinating regions of multiple sclerosis brains. Ann. Neurol. 36, 778-786. doi: 10.1002/ana.410360515

Bodini, B., Veronese, M., Garcia-Lorenzo, D., Battaglini, M., Poirion, E., Chardain, A., et al. (2016). Dynamic imaging of individual remyelination profiles in multiple sclerosis. Ann. Neurol. 79, 726-738. doi: 10.1002/ana.24620

Boiko, T., Rasband, M. N., Levinson, S. R., Caldwell, J. H., Mandel, G., Trimmer, J. S., et al. (2001). Compact myelin dictates the differential targeting of two sodium channel isoforms in the same axon. Neuron 30, 91-104. doi: 10.1016/ S0896-6273(01)00265-3

Boison, D., and Stoffel, W. (1994). Disruption of the compacted myelin sheath of axons of the central nervous system in proteolipid protein-deficient mice. Proc. Natl. Acad. Sci. U.S.A. 91, 11709-11713. doi: 10.1073/pnas.91.24.11709

Brand-Schieber, E., and Werner, P. (2004). Calcium channel blockers ameliorate disease in a mouse model of multiple sclerosis. Exp. Neurol. 189, 5-9. doi: 10.1016/j.expneurol.2004.05.023

Braun, P. E., Sandillon, F., Edwards, A., Matthieu, J. M., and Privat, A. (1988). Immunocytochemical localization by electron microscopy of 2'3'-cyclic nucleotide 3'-phosphodiesterase in developing oligodendrocytes of normal and mutant brain. J. Neurosci. 8, 3057-3066. doi: 10.1523/JNEUROSCI.08-0803057.1988

Brivio, V., Faivre-Sarrailh, C., Peles, E., Sherman, D. L., and Brophy, P. J. (2017). Assembly of CNS nodes of ranvier in myelinated nerves is promoted by the axon cytoskeleton. Curr. Biol. 27, 1068-1073. doi: 10.1016/j.cub.2017.01.025

Brown, G. C., and Cooper, C. E. (1994). Nanomolar concentrations of nitric oxide reversibly inhibit synaptosomal respiration by competing with oxygen at cytochrome oxidase. FEBS Lett. 356, 295-298. doi: 10.1016/0014-5793(94) 01290-3

Buchheit, T. E., and Tytell, M. (1992). Transfer of molecules from glia to axon in the squid may be mediated by glial vesicles. J. Neurobiol. 23, 217-230. doi: 10.1002/neu.480230303

Buschmann, J. P., Berger, K., Awad, H., Clarner, T., Beyer, C., and Kipp, M. (2012). Inflammatory response and chemokine expression in the white matter corpus callosum and gray matter cortex region during cuprizone-induced demyelination. J. Mol. Neurosci. 48, 66-76. doi: 10.1007/s12031-012-9773-x

Cadavid, D., Mellion, M., Hupperts, R., Edwards, K. R., Calabresi, P. A., Drulovic, J., et al. (2019). Safety and efficacy of opicinumab in patients with relapsing multiple sclerosis (SYNERGY): a randomised, placebo-controlled, phase 2 trial. Lancet Neurol. 18, 845-856. doi: 10.1016/S1474-4422(19)30137-1

Caldwell, J. H., Schaller, K. L., Lasher, R. S., Peles, E., and Levinson, S. R. (2000). Sodium channel $\mathrm{Na}(\mathrm{v}) 1.6$ is localized at nodes of ranvier, dendrites, and synapses. Proc. Natl. Acad. Sci. U.S.A. 97, 5616-5620. doi: 10.1073/pnas. 090034797

Calvo, S. E., Clauser, K. R., and Mootha, V. K. (2016). MitoCarta2.0: an updated inventory of mammalian mitochondrial proteins. Nucleic Acids Res. 44, D1251D1257. doi: 10.1093/nar/gkv1003

Cambron, M., D’haeseleer, M., Laureys, G., Clinckers, R., Debruyne, J., and De Keyser, J. (2012). White-matter astrocytes, axonal energy metabolism, and axonal degeneration in multiple sclerosis. J. Cereb. Blood Flow Metab. 32, 413-424. doi: 10.1038/jcbfm.2011.193

Campbell, G., Licht-Mayer, S., and Mahad, D. (2019). Targeting mitochondria to protect axons in progressive MS. Neurosci. Lett. 710:134258. doi: 10.1016/j. neulet.2019.05.012

Campbell, G. R., Kraytsberg, Y., Krishnan, K. J., Ohno, N., Ziabreva, I., Reeve, A., et al. (2012). Clonally expanded mitochondrial DNA deletions within the choroid plexus in multiple sclerosis. Acta Neuropathol. 124, 209-220. doi: 10. 1007/s00401-012-1001-9

Campbell, G. R., Ziabreva, I., Reeve, A. K., Krishnan, K. J., Reynolds, R., Howell, O., et al. (2011). Mitochondrial DNA deletions and neurodegeneration in multiple sclerosis. Ann. Neurol. 69, 481-492. doi: 10.1002/ana.22109

Caprariello, A. V., Mangla, S., Miller, R. H., and Selkirk, S. M. (2012). Apoptosis of oligodendrocytes in the central nervous system results in rapid focal demyelination. Ann. Neurol. 72, 395-405. doi: 10.1002/ana. 23606

Charles, P., Tait, S., Faivre-Sarrailh, C., Barbin, G., Gunn-Moore, F., DenisenkoNehrbass, N., et al. (2002). Neurofascin is a glial receptor for the paranodin/Caspr-contactin axonal complex at the axoglial junction. Curr. Biol. 12, 217-220. doi: 10.1016/S0960-9822(01)00680-7
Chen, W. T., Lu, A., Craessaerts, K., Pavie, B., Sala Frigerio, C., Corthout, N., et al. (2020). Spatial transcriptomics and in situ sequencing to study Alzheimer's disease. Cell 182, 976.e9-991.e9. doi: 10.1016/j.cell.2020.06.038

Chitnis, T., Imitola, J., Wang, Y., Elyaman, W., Chawla, P., Sharuk, M., et al. (2007). Elevated neuronal expression of CD200 protects Wlds mice from inflammation-mediated neurodegeneration. Am. J. Pathol. 170, 1695-1712. doi: 10.2353/ajpath.2007.060677

Chong, S. Y., Rosenberg, S. S., Fancy, S. P., Zhao, C., Shen, Y. A., Hahn, A. T., et al. (2012). Neurite outgrowth inhibitor Nogo-A establishes spatial segregation and extent of oligodendrocyte myelination. Proc. Natl. Acad. Sci. U.S.A. 109, 1299-1304. doi: 10.1073/pnas.1113540109

Cleeter, M. W., Cooper, J. M., Darley-Usmar, V. M., Moncada, S., and Schapira, A. H. (1994). Reversible inhibition of cytochrome $c$ oxidase, the terminal enzyme of the mitochondrial respiratory chain, by nitric oxide. Implications for neurodegenerative diseases. FEBS Lett. 345, 50-54. doi: 10.1016/0014-5793(94) 00424-2

Coetzee, T., Suzuki, K., Nave, K. A., and Popko, B. (1999). Myelination in the absence of galactolipids and proteolipid proteins. Mol. Cell. Neurosci. 14, 41-51. doi: 10.1006/mcne.1999.0768

Cohen, C. C. H., Popovic, M. A., Klooster, J., Weil, M. T., Mobius, W., Nave, K. A., et al. (2020). Saltatory conduction along myelinated axons involves a periaxonal nanocircuit. Cell 180, 311.e5-322.e5. doi: 10.1016/j.cell.2019.11.039

Coleman, M. P., and Hoke, A. (2020). Programmed axon degeneration: from mouse to mechanism to medicine. Nat. Rev. Neurosci. 21, 183-196. doi: 10. 1038/s41583-020-0269-3

Coman, I., Aigrot, M. S., Seilhean, D., Reynolds, R., Girault, J. A., Zalc, B., et al. (2006). Nodal, paranodal and juxtaparanodal axonal proteins during demyelination and remyelination in multiple sclerosis. Brain 129, 3186-3195. doi: 10.1093/brain/awl144

Connern, C. P., and Halestrap, A. P. (1996). Chaotropic agents and increased matrix volume enhance binding of mitochondrial cyclophilin to the inner mitochondrial membrane and sensitize the mitochondrial permeability transition to [Ca2+]. Biochemistry 35, 8172-8180. doi: 10.1021/bi9525177

Craner, M. J., Damarjian, T. G., Liu, S., Hains, B. C., Lo, A. C., Black, J. A., et al. (2005). Sodium channels contribute to microglia/macrophage activation and function in EAE and MS. Glia 49, 220-229. doi: 10.1002/glia.20112

Craner, M. J., Lo, A. C., Black, J. A., and Waxman, S. G. (2003). Abnormal sodium channel distribution in optic nerve axons in a model of inflammatory demyelination. Brain 126, 1552-1561. doi: 10.1093/brain/awg153

Craner, M. J., Newcombe, J., Black, J. A., Hartle, C., Cuzner, M. L., and Waxman, S. G. (2004). Molecular changes in neurons in multiple sclerosis: altered axonal expression of Nav1.2 and Nav1.6 sodium channels and $\mathrm{Na}+/ \mathrm{Ca} 2+$ exchanger. Proc. Natl. Acad. Sci. U.S.A. 101, 8168-8173. doi: 10.1073/pnas.0402765101

Cross, A. H., Keeling, R. M., Goorha, S., San, M., Rodi, C., Wyatt, P. S., et al. (1996). Inducible nitric oxide synthase gene expression and enzyme activity correlate with disease activity in murine experimental autoimmune encephalomyelitis. J. Neuroimmunol. 71, 145-153. doi: 10.1016/S0165-5728(96)00147-6

Cullen, C. L., Pepper, R. E., Clutterbuck, M. T., Pitman, K. A., Oorschot, V., Auderset, L., et al. (2021). Periaxonal and nodal plasticities modulate action potential conduction in the adult mouse brain. Cell. Rep. 34:108641. doi: 10. 1016/j.celrep.2020.108641

De Stefani, D., Raffaello, A., Teardo, E., Szabo, I., and Rizzuto, R. (2011). A forty-kilodalton protein of the inner membrane is the mitochondrial calcium uniporter. Nature 476, 336-340. doi: 10.1038/nature10230

De Stefano, N., Giorgio, A., Battaglini, M., Rovaris, M., Sormani, M. P., Barkhof, F., et al. (2010). Assessing brain atrophy rates in a large population of untreated multiple sclerosis subtypes. Neurology 74, 1868-1876. doi: 10.1212/WNL. 0b013e3181e24136

De Stefano, N., Narayanan, S., Francis, G. S., Arnaoutelis, R., Tartaglia, M. C., Antel, J. P., et al. (2001). Evidence of axonal damage in the early stages of multiple sclerosis and its relevance to disability. Arch. Neurol. 58, 65-70. doi: 10.1001/archneur.58.1.65

Denton, R. M., Randle, P. J., and Martin, B. R. (1972). Stimulation by calcium ions of pyruvate dehydrogenase phosphate phosphatase. Biochem. J. 128, 161-163. doi: 10.1042/bj1280161

Derfuss, T., Mehling, M., Papadopoulou, A., Bar-Or, A., Cohen, J. A., and Kappos, L. (2020). Advances in oral immunomodulating therapies in relapsing multiple sclerosis. Lancet Neurol. 19, 336-347. doi: 10.1016/S1474-4422(19)30391-6 
DiMauro, S., and Schon, E. A. (2003). Mitochondrial respiratory-chain diseases. N. Engl. J. Med. 348, 2656-2668. doi: 10.1056/NEJMra022567

Dubessy, A. L., Mazuir, E., Rappeneau, Q., Ou, S., Abi Ghanem, C., Piquand, K., et al. (2019). Role of a Contactin multi-molecular complex secreted by oligodendrocytes in nodal protein clustering in the CNS. Glia 67, 2248-2263. doi: 10.1002/glia.23681

Duncan, G. J., Manesh, S. B., Hilton, B. J., Assinck, P., Liu, J., Moulson, A., et al. (2018). Locomotor recovery following contusive spinal cord injury does not require oligodendrocyte remyelination. Nat. Commun. 9:3066. doi: 10.1038/ s41467-018-05473-1

Duncan, G. J., Manesh, S. B., Hilton, B. J., Assinck, P., Plemel, J. R., and Tetzlaff, W. (2020). The fate and function of oligodendrocyte progenitor cells after traumatic spinal cord injury. Glia 68, 227-245. doi: 10.1002/glia.23706

Duncan, G. J., Plemel, J. R., Assinck, P., Manesh, S. B., Muir, F. G. W., Hirata, R., et al. (2017). Myelin regulatory factor drives remyelination in multiple sclerosis. Acta Neuropathol. 134, 403-422. doi: 10.1007/s00401-017-1741-7

Duncan, I. D., Marik, R. L., Broman, A. T., and Heidari, M. (2017). Thin myelin sheaths as the hallmark of remyelination persist over time and preserve axon function. Proc. Natl. Acad. Sci. U.S.A. 114, E9685-E9691. doi: 10.1073/pnas. 1714183114

Dupree, J. L., Mason, J. L., Marcus, J. R., Stull, M., Levinson, R., Matsushima, G. K., et al. (2004). Oligodendrocytes assist in the maintenance of sodium channel clusters independent of the myelin sheath. Neuron Glia Biol. 1, 179-192. doi: 10.1017/S1740925X04000304

Dutta, R., Chang, A., Doud, M. K., Kidd, G. J., Ribaudo, M. V., Young, E. A., et al. (2011). Demyelination causes synaptic alterations in hippocampi from multiple sclerosis patients. Ann. Neurol. 69, 445-454. doi: 10.1002/ana.22337

Dutta, R., Chomyk, A. M., Chang, A., Ribaudo, M. V., Deckard, S. A., Doud, M. K., et al. (2013). Hippocampal demyelination and memory dysfunction are associated with increased levels of the neuronal microRNA miR-124 and reduced AMPA receptors. Ann. Neurol. 73, 637-645. doi: 10.1002/ana.23860

Dutta, R., Mcdonough, J., Chang, A., Swamy, L., Siu, A., Kidd, G. J., et al. (2007). Activation of the ciliary neurotrophic factor (CNTF) signalling pathway in cortical neurons of multiple sclerosis patients. Brain 130, 2566-2576. doi: 10. 1093/brain/awm206

Dutta, R., Mcdonough, J., Yin, X. G., Peterson, J., Chang, A., Torres, T., et al. (2006). Mitochondrial dysfunction as a cause of axonal degeneration in multiple sclerosis patients. Ann. Neurol. 59, 478-489. doi: 10.1002/ana.20736

Dutta, R., and Trapp, B. D. (2011). Mechanisms of neuronal dysfunction and degeneration in multiple sclerosis. Prog. Neurobiol. 93, 1-12. doi: 10.1016/j. pneurobio.2010.09.005

Dziedzic, T., Metz, I., Dallenga, T., Konig, F. B., Muller, S., Stadelmann, C., et al. (2010). Wallerian degeneration: a major component of early axonal pathology in multiple sclerosis. Brain Pathol. 20, 976-985. doi: 10.1111/j.1750-3639.2010. 00401.x

Edgar, J. M., Mclaughlin, M., Werner, H. B., Mcculloch, M. C., Barrie, J. A., Brown, A., et al. (2009). Early ultrastructural defects of axons and axon-glia junctions in mice lacking expression of Cnp1. Glia 57, 1815-1824. doi: 10.1002/glia.20893

Edgar, J. M., Mclaughlin, M., Yool, D., Zhang, S. C., Fowler, J. H., Montague, P., et al. (2004). Oligodendroglial modulation of fast axonal transport in a mouse model of hereditary spastic paraplegia. J. Cell Biol. 166, 121-131. doi: $10.1083 /$ jcb. 200312012

Elitt, M. S., Shick, H. E., Madhavan, M., Allan, K. C., Clayton, B. L. L., Weng, C., et al. (2018). Chemical screening identifies enhancers of mutant oligodendrocyte survival and unmasks a distinct pathological phase in pelizaeus-merzbacher disease. Stem Cell Rep. 11, 711-726. doi: 10.1016/j.stemcr. 2018.07.015

England, J. D., Gamboni, F., and Levinson, S. R. (1991). Increased numbers of sodium channels form along demyelinated axons. Brain Res. 548, 334-337. doi: 10.1016/0006-8993(91)91144-P

Eykens, C., Rossaert, E., Duqué, S., Rué, L., Bento-Abreu, A., Hersmus, N., et al. (2021). AAV9-mediated gene delivery of MCT1 to oligodendrocytes does not provide a therapeutic benefit in a mouse model of ALS. Mol. Ther. Meth. Clin. D 20, 508-519. doi: 10.1016/j.omtm.2021.01.006

Falcao, A. M., Van Bruggen, D., Marques, S., Meijer, M., Jakel, S., Agirre, E., et al. (2018). Disease-specific oligodendrocyte lineage cells arise in multiple sclerosis. Nat. Med. 24, 1837-1844. doi: 10.1038/s41591-018$0236-\mathrm{y}$
Fallarino, F., Volpi, C., Fazio, F., Notartomaso, S., Vacca, C., Busceti, C., et al. (2010). Metabotropic glutamate receptor-4 modulates adaptive immunity and restrains neuroinflammation. Nat. Med. 16, 897-902. doi: 10.1038/nm.2183

Farjam, M., Beigi Zarandi, F. B., Farjadian, S., Geramizadeh, B., Nikseresht, A. R., and Panjehshahin, M. R. (2014). Inhibition of NR2B-containing $\mathrm{N}$-methyl-D-aspartate receptors (NMDARs) in experimental autoimmune encephalomyelitis, a model of multiple sclerosis. Iran. J. Pharm. Res. 13, 695705.

Fasciani, I., Pluta, P., Gonzalez-Nieto, D., Martinez-Montero, P., Molano, J., Paino, C. L., et al. (2018). Directional coupling of oligodendrocyte connexin-47 and astrocyte connexin-43 gap junctions. Glia 66, 2340-2352. doi: 10.1002/glia. 23471

Fazio, F., Zappulla, C., Notartomaso, S., Busceti, C., Bessede, A., Scarselli, P., et al. (2014). Cinnabarinic acid, an endogenous agonist of type-4 metabotropic glutamate receptor, suppresses experimental autoimmune encephalomyelitis in mice. Neuropharmacology 81, 237-243. doi: 10.1016/j.neuropharm.2014.02.011

Felts, P. A., Baker, T. A., and Smith, K. J. (1997). Conduction in segmentally demyelinated mammalian central axons. J. Neurosci. 17, 7267-7277. doi: 10. 1523/JNEUROSCI.17-19-07267.1997

Ferguson, B., Matyszak, M. K., Esiri, M. M., and Perry, V. H. (1997). Axonal damage in acute multiple sclerosis lesions. Brain 120(Pt 3), 393-399. doi: 10. 1093/brain/120.3.393

Filippi, M., Bozzali, M., Rovaris, M., Gonen, O., Kesavadas, C., Ghezzi, A., et al. (2003). Evidence for widespread axonal damage at the earliest clinical stage of multiple sclerosis. Brain 126, 433-437. doi: 10.1093/brain/awg038

Forte, M., Gold, B. G., Marracci, G., Chaudhary, P., Basso, E., Johnsen, D., et al. (2007). Cyclophilin D inactivation protects axons in experimental autoimmune encephalomyelitis, an animal model of multiple sclerosis. Proc. Natl. Acad. Sci. U.S.A. 104, 7558-7563. doi: 10.1073/pnas.0702228104

Fourcade, S., Lopez-Erauskin, J., Galino, J., Duval, C., Naudi, A., Jove, M., et al. (2008). Early oxidative damage underlying neurodegeneration in X-adrenoleukodystrophy. Hum. Mol. Genet. 17, 1762-1773. doi: 10.1093/hmg/ ddn085

Franklin, R. J., Ffrench-Constant, C., Edgar, J. M., and Smith, K. J. (2012). Neuroprotection and repair in multiple sclerosis. Nat. Rev. Neurol. 8, 624-634. doi: $10.1038 /$ nrneurol.2012.200

Franklin, R. J. M., and Ffrench-Constant, C. (2017). Regenerating CNS myelin from mechanisms to experimental medicines. Nat. Rev. Neurosci. 18, 753-769. doi: $10.1038 / \mathrm{nrn} .2017 .136$

Freeman, M. R. (2014). Signaling mechanisms regulating Wallerian degeneration. Curr. Opin. Neurobiol. 27, 224-231. doi: 10.1016/j.conb.2014.05.001

Freeman, S. A., Desmazieres, A., Simonnet, J., Gatta, M., Pfeiffer, F., Aigrot, M. S., et al. (2015). Acceleration of conduction velocity linked to clustering of nodal components precedes myelination. Proc. Natl. Acad. Sci. U.S.A. 112, E321-E328. doi: 10.1073/pnas.1419099112

Friese, M. A., Schattling, B., and Fugger, L. (2014). Mechanisms of neurodegeneration and axonal dysfunction in multiple sclerosis. Nat. Rev. Neurol. 10, 225-238. doi: 10.1038/nrneurol.2014.37

Frischer, J. M., Weigand, S. D., Guo, Y., Kale, N., Parisi, J. E., Pirko, I., et al. (2015). Clinical and pathological insights into the dynamic nature of the white matter multiple sclerosis plaque. Ann. Neurol. 78, 710-721. doi: 10.1002/ana.24497

Fruhbeis, C., Frohlich, D., Kuo, W. P., Amphornrat, J., Thilemann, S., Saab, A. S., et al. (2013). Neurotransmitter-triggered transfer of exosomes mediates oligodendrocyte-neuron communication. PLoS Biol. 11:e1001604. doi: 10.1371/ journal.pbio.1001604

Frühbeis, C., Kuo-Elsner, W. P., Müller, C., Barth, K., Peris, L., Tenzer, S., et al. (2020). Oligodendrocytes support axonal transport and maintenance via exosome secretion. bioRxiv [Preprint].

Fruhbeis, C., Kuo-Elsner, W. P., Muller, C., Barth, K., Peris, L., Tenzer, S., et al. (2020). Oligodendrocytes support axonal transport and maintenance via exosome secretion. PLoS Biol. 18:e3000621. doi: 10.1371/journal.pbio.3000621

Fu, L., Matthews, P. M., De Stefano, N., Worsley, K. J., Narayanan, S., Francis, G. S., et al. (1998). Imaging axonal damage of normal-appearing white matter in multiple sclerosis. Brain 121(Pt 1), 103-113. doi: 10.1093/brain/121.1.103

Fu, Y., Frederick, T. J., Huff, T. B., Goings, G. E., Miller, S. D., and Cheng, J. X. (2011). Paranodal myelin retraction in relapsing experimental autoimmune encephalomyelitis visualized by coherent anti-Stokes Raman scattering microscopy. J. Biomed. Opt. 16:106006. doi: 10.1117/1.3638180 
Funfschilling, U., Supplie, L. M., Mahad, D., Boretius, S., Saab, A. S., Edgar, J., et al. (2012). Glycolytic oligodendrocytes maintain myelin and long-term axonal integrity. Nature 485, 517-521. doi: 10.1038/nature11007

Gadjanski, I., Boretius, S., Williams, S. K., Lingor, P., Knoferle, J., Sattler, M. B., et al. (2009). Role of $n$-type voltage-dependent calcium channels in autoimmune optic neuritis. Ann. Neurol. 66, 81-93. doi: 10.1002/ana.21668

Garbern, J. Y., Yool, D. A., Moore, G. J., Wilds, I. B., Faulk, M. W., Klugmann, M., et al. (2002). Patients lacking the major CNS myelin protein, proteolipid protein 1, develop length-dependent axonal degeneration in the absence of demyelination and inflammation. Brain 125, 551-561. doi: 10.1093/brain/ awf043

Gaudet, A. D., Popovich, P. G., and Ramer, M. S. (2011). Wallerian degeneration: gaining perspective on inflammatory events after peripheral nerve injury. J. Neuroinflammation 8:110. doi: 10.1186/1742-2094-8-110

George, E. B., Glass, J. D., and Griffin, J. W. (1995). Axotomy-induced axonal degeneration is mediated by calcium influx through ion-specific channels. J. Neurosci. 15, 6445-6452. doi: 10.1523/JNEUROSCI.15-10-06445. 1995

Gerdts, J., Summers, D. W., Milbrandt, J., and Diantonio, A. (2016). Axon selfdestruction: new links among SARM1, MAPKs, and NAD plus metabolism. Neuron 89, 449-460. doi: 10.1016/j.neuron.2015.12.023

Geurts, J. J., Wolswijk, G., Bo, L., Van Der Valk, P., Polman, C. H., Troost, D., et al. (2003). Altered expression patterns of group I and II metabotropic glutamate receptors in multiple sclerosis. Brain 126, 1755-1766. doi: 10.1093/ brain/awg179

Gilley, J., and Coleman, M. P. (2010). Endogenous Nmnat2 is an essential survival factor for maintenance of healthy axons. PLoS Biol. 8:e1000300. doi: 10.1371/ journal.pbio. 1000300

Gleichmann, M., and Mattson, M. P. (2011). Neuronal calcium homeostasis and dysregulation. Antioxid. Redox. Signal. 14, 1261-1273. doi: 10.1089/ars.2010. 3386

Goldschmidt, T., Antel, J., Konig, F. B., Bruck, W., and Kuhlmann, T. (2009). Remyelination capacity of the MS brain decreases with disease chronicity. Neurology 72, 1914-1921. doi: 10.1212/WNL.0b013e3181a $8260 \mathrm{a}$

Green, A. J., Gelfand, J. M., Cree, B. A., Bevan, C., Boscardin, W. J., Mei, F., et al. (2017). Clemastine fumarate as a remyelinating therapy for multiple sclerosis (ReBUILD): a randomised, controlled, double-blind, crossover trial. Lancet 390, 2481-2489. doi: 10.1016/S0140-6736(17)32346-2

Griffiths, I., Klugmann, M., Anderson, T., Yool, D., Thomson, C., Schwab, M. H., et al. (1998). Axonal swellings and degeneration in mice lacking the major proteolipid of myelin. Science 280, 1610-1613. doi: 10.1126/science.280.5369. 1610

Grubman, A., Chew, G., Ouyang, J. F., Sun, G., Choo, X. Y., Mclean, C., et al. (2019). A single-cell atlas of entorhinal cortex from individuals with Alzheimer's disease reveals cell-type-specific gene expression regulation. Nat. Neurosci. 22, 2087-2097. doi: 10.1038/s41593-019-0539-4

Gudi, V., Gingele, S., Skripuletz, T., and Stangel, M. (2014). Glial response during cuprizone-induced de- and remyelination in the CNS: lessons learned. Front. Cell. Neurosci. 8:73. doi: 10.3389/fncel.2014.00073

Guest, J. D., Hiester, E. D., and Bunge, R. P. (2005). Demyelination and Schwann cell responses adjacent to injury epicenter cavities following chronic human spinal cord injury. Exp. Neurol. 192, 384-393. doi: 10.1016/j.expneurol.2004. 11.033

Haider, L., Fischer, M. T., Frischer, J. M., Bauer, J., Hoftberger, R., Botond, G., et al. (2011). Oxidative damage in multiple sclerosis lesions. Brain 134, 1914-1924. doi: 10.1093/brain/awr128

Hamada, M. S., and Kole, M. H. (2015). Myelin loss and axonal ion channel adaptations associated with gray matter neuronal hyperexcitability. J. Neurosci. 35, 7272-7286. doi: 10.1523/JNEUROSCI.4747-14.2015

Harris, J. J., and Attwell, D. (2012). The energetics of CNS white matter. J. Neurosci. 32, 356-371. doi: 10.1523/JNEUROSCI.3430-11.2012

Hartley, M. D., Banerji, T., Tagge, I. J., Kirkemo, L. L., Chaudhary, P., Calkins, E., et al. (2019). Myelin repair stimulated by CNS-selective thyroid hormone action. JCI Insight 4:e126329. doi: 10.1172/jci.insight.126329

Hartline, D. K., and Colman, D. R. (2007). Rapid conduction and the evolution of giant axons and myelinated fibers. Curr. Biol. 17, R29-R35. doi: 10.1016/j.cub. 2006.11.042
Hassen, G. W., Feliberti, J., Kesner, L., Stracher, A., and Mokhtarian, F. (2008). Prevention of axonal injury using calpain inhibitor in chronic progressive experimental autoimmune encephalomyelitis. Brain Res. 1236, 206-215. doi: 10.1016/j.brainres.2008.07.124

Hayton, T., Furby, J., Smith, K. J., Altmann, D. R., Brenner, R., Chataway, J., et al. (2012). Longitudinal changes in magnetisation transfer ratio in secondary progressive multiple sclerosis: data from a randomised placebo controlled trial of lamotrigine. J. Neurol. 259, 505-514. doi: 10.1007/s00415-011-6212-9

Holm, M. M., Kaiser, J., and Schwab, M. E. (2018). Extracellular vesicles: multimodal envoys in neural maintenance and repair. Trends Neurosci. 41, 360-372. doi: 10.1016/j.tins.2018.03.006

Holman, S. P., Lobo, A. S., Novorolsky, R. J., Nichols, M., Fiander, M. D. J., Konda, P., et al. (2020). Neuronal mitochondrial calcium uniporter deficiency exacerbates axonal injury and suppresses remyelination in mice subjected to experimental autoimmune encephalomyelitis. Exp. Neurol. 333:113430. doi: 10.1016/j.expneurol.2020.113430

Howell, O. W., Palser, A., Polito, A., Melrose, S., Zonta, B., Scheiermann, C., et al. (2006). Disruption of neurofascin localization reveals early changes preceding demyelination and remyelination in multiple sclerosis. Brain 129, 3173-3185. doi: 10.1093/brain/awl290

Hoy, A. R., Ly, M., Carlsson, C. M., Okonkwo, O. C., Zetterberg, H., Blennow, K., et al. (2017). Microstructural white matter alterations in preclinical Alzheimer's disease detected using free water elimination diffusion tensor imaging. PLoS One 12:e0173982. doi: 10.1371/journal.pone.0173982

Hsu, C., Morohashi, Y., Yoshimura, S., Manrique-Hoyos, N., Jung, S., Lauterbach, M. A., et al. (2010). Regulation of exosome secretion by Rab35 and its GTPaseactivating proteins TBC1D10A-C. J. Cell Biol. 189, 223-232. doi: 10.1083/jcb. 200911018

Hughes, E. G., Orthmann-Murphy, J. L., Langseth, A. J., and Bergles, D. E. (2018). Myelin remodeling through experience-dependent oligodendrogenesis in the adult somatosensory cortex. Nat. Neurosci. 21, 696-706. doi: /10.1038/s41593018-0121-5

Igbavboa, U., and Pfeiffer, D. R. (1988). EGTA inhibits reverse uniport-dependent $\mathrm{Ca} 2+$ release from uncoupled mitochondria. Possible regulation of the $\mathrm{Ca} 2+$ uniporter by a $\mathrm{Ca} 2+$ binding site on the cytoplasmic side of the inner membrane. J. Biol. Chem. 263, 1405-1412. doi: 10.1016/S0021-9258(19) 57318-5

Ingwersen, J., De Santi, L., Wingerath, B., Graf, J., Koop, B., Schneider, R., et al. (2018). Nimodipine confers clinical improvement in two models of experimental autoimmune encephalomyelitis. J. Neurochem. [Epub ahead of print]. doi: 10.1111/jnc. 14324

Inoue, K. (2019). Pelizaeus-merzbacher disease: molecular and cellular pathologies and associated phenotypes. Adv. Exp. Med. Biol. 1190, 201-216. doi: 10.1007/ 978-981-32-9636-7_13

Ip, C. W., Kroner, A., Bendszus, M., Leder, C., Kobsar, I., Fischer, S., et al. (2006). Immune cells contribute to myelin degeneration and axonopathic changes in mice overexpressing proteolipid protein in oligodendrocytes. J. Neurosci. 26, 8206-8216. doi: 10.1523/JNEUROSCI.1921-06.2006

Irvine, K. A., and Blakemore, W. F. (2006). Age increases axon loss associated with primary demyelination in cuprizone-induced demyelination in C57BL/6 mice. J. Neuroimmunol. 175, 69-76. doi: 10.1016/j.jneuroim.2006.03.002

Irvine, K. A., and Blakemore, W. F. (2007). A different regional response by mouse oligodendrocyte progenitor cells (OPCs) to high-dose X-irradiation has consequences for repopulating OPC-depleted normal tissue. Eur. J. Neurosci. 25, 417-424. doi: 10.1111/j.1460-9568.2007.05313.x

Irvine, K. A., and Blakemore, W. F. (2008). Remyelination protects axons from demyelination-associated axon degeneration. Brain 131, 1464-1477. doi: 10. 1093/brain/awn080

Jahn, O., Siems, S. B., Kusch, K., Hesse, D., Jung, R. B., Liepold, T., et al. (2020). The CNS myelin proteome: deep profile and persistence after post-mortem delay. Front. Cell. Neurosci. 14:239. doi: 10.3389/fncel.2020.00239

Jakel, S., Agirre, E., Mendanha Falcao, A., Van Bruggen, D., Lee, K. W., Knuesel, I., et al. (2019). Altered human oligodendrocyte heterogeneity in multiple sclerosis. Nature 566, 543-547. doi: 10.1038/s41586-019-0903-2

James, N. D., Bartus, K., Grist, J., Bennett, D. L., Mcmahon, S. B., and Bradbury, E. J. (2011). Conduction failure following spinal cord injury: functional and anatomical changes from acute to chronic stages. J. Neurosci. 31, 18543-18555. doi: 10.1523/JNEUROSCI.4306-11.2011 
Jhelum, P., Santos-Nogueira, E., Teo, W., Haumont, A., Lenoel, I., Stys, P. K., et al. (2020). Ferroptosis mediates cuprizone-induced loss of oligodendrocytes and demyelination. J. Neurosci. 40, 9327-9341. doi: 10.1523/JNEUROSCI.1749-20. 2020

Joshi, D. C., Zhang, C. L., Lin, T. M., Gusain, A., Harris, M. G., Tree, E., et al. (2015). Deletion of mitochondrial anchoring protects dysmyelinating shiverer: implications for progressive MS. J. Neurosci. 35, 5293-5306. doi: 10.1523/ JNEUROSCI.3859-14.2015

Jurgens, T., Jafari, M., Kreutzfeldt, M., Bahn, E., Bruck, W., Kerschensteiner, M., et al. (2016). Reconstruction of single cortical projection neurons reveals primary spine loss in multiple sclerosis. Brain 139, 39-46. doi: 10.1093/brain/ awv353

Kagawa, T., Ikenaka, K., Inoue, Y., Kuriyama, S., Tsujii, T., Nakao, J., et al. (1994). Glial cell degeneration and hypomyelination caused by overexpression of myelin proteolipid protein gene. Neuron 13, 427-442. doi: 10.1016/08966273(94)90358-1

Kakulas, B. A. (2004). Neuropathology: the foundation for new treatments in spinal cord injury. Spinal Cord 42, 549-563. doi: 10.1038/sj.sc.3101670

Kamakura, K., Ishiura, S., Sugita, H., and Toyokura, Y. (1983). Identification of $\mathrm{Ca} 2+$-activated neutral protease in the peripheral nerve and its effects on neurofilament degeneration. J. Neurochem. 40, 908-913. doi: 10.1111/j.14714159.1983.tb08072.x

Kamasawa, N., Sik, A., Morita, M., Yasumura, T., Davidson, K. G., Nagy, J. I., et al. (2005). Connexin-47 and connexin-32 in gap junctions of oligodendrocyte somata, myelin sheaths, paranodal loops and Schmidt-Lanterman incisures: implications for ionic homeostasis and potassium siphoning. Neuroscience 136, 65-86. doi: 10.1016/j.neuroscience.2005.08.027

Kaneko, S., Wang, J., Kaneko, M., Yiu, G., Hurrell, J. M., Chitnis, T., et al. (2006). Protecting axonal degeneration by increasing nicotinamide adenine dinucleotide levels in experimental autoimmune encephalomyelitis models. J. Neurosci. 26, 9794-9804. doi: 10.1523/JNEUROSCI.2116-06.2006

Kang, J. S., Tian, J. H., Pan, P. Y., Zald, P., Li, C., Deng, C., et al. (2008). Docking of axonal mitochondria by syntaphilin controls their mobility and affects short-term facilitation. Cell 132, 137-148. doi: 10.1016/j.cell.2007.11.024

Kang, S. H., Li, Y., Fukaya, M., Lorenzini, I., Cleveland, D. W., Ostrow, L. W., et al. (2013). Degeneration and impaired regeneration of gray matter oligodendrocytes in amyotrophic lateral sclerosis. Nat. Neurosci. 16, 571-579. doi: 10.1038/nn.3357

Kaplan, M. R., Meyer-Franke, A., Lambert, S., Bennett, V., Duncan, I. D., Levinson, S. R., et al. (1997). Induction of sodium channel clustering by oligodendrocytes. Nature 386, 724-728. doi: 10.1038/386724a0

Kapoor, R., Davies, M., Blaker, P. A., Hall, S. M., and Smith, K. J. (2003). Blockers of sodium and calcium entry protect axons from nitric oxide-mediated degeneration. Ann. Neurol. 53, 174-180. doi: 10.1002/ana.10443

Kapoor, R., Furby, J., Hayton, T., Smith, K. J., Altmann, D. R., Brenner, R., et al. (2010). Lamotrigine for neuroprotection in secondary progressive multiple sclerosis: a randomised, double-blind, placebo-controlled, parallel-group trial. Lancet Neurol. 9, 681-688. doi: 10.1016/S1474-4422(10)70131-9

Karim, S. A., Barrie, J. A., Mcculloch, M. C., Montague, P., Edgar, J. M., Kirkham, D., et al. (2007). PLP overexpression perturbs myelin protein composition and myelination in a mouse model of Pelizaeus-Merzbacher disease. Glia 55, 341-351. doi: 10.1002/glia.20465

Kassmann, C. M., Lappe-Siefke, C., Baes, M., Brugger, B., Mildner, A., Werner, H. B., et al. (2007). Axonal loss and neuroinflammation caused by peroxisomedeficient oligodendrocytes. Nat. Genet. 39, 969-976. doi: 10.1038/ng2070

Kettenmann, H., Orkand, R. K., and Schachner, M. (1983). Coupling among identified cells in mammalian nervous system cultures. J. Neurosci. 3, 506-516. doi: 10.1523/JNEUROSCI.03-03-00506.1983

Kim, J. H., Budde, M. D., Liang, H. F., Klein, R. S., Russell, J. H., Cross, A. H., et al. (2006). Detecting axon damage in spinal cord from a mouse model of multiple sclerosis. Neurobiol. Dis. 21, 626-632. doi: 10.1016/j.nbd.2005.09.009

Kim, J. Y., Shen, S., Dietz, K., He, Y., Howell, O., Reynolds, R., et al. (2010). HDAC1 nuclear export induced by pathological conditions is essential for the onset of axonal damage. Nat. Neurosci. 13, 180-189. doi: 10.1038/nn.2471

Kim, S., Chung, A. Y., Na, J. E., Lee, S. J., Jeong, S. H., Kim, E., et al. (2019). Myelin degeneration induced by mutant superoxide dismutase 1 accumulation promotes amyotrophic lateral sclerosis. Glia 67, 1910-1921. doi: 10.1002/glia. 23669
Kipp, M., Van Der Star, B., Vogel, D. Y., Puentes, F., Van Der Valk, P., Baker, D., et al. (2012). Experimental in vivo and in vitro models of multiple sclerosis: EAE and beyond. Mult. Scler. Relat. Disord. 1, 15-28. doi: 10.1016/j.msard.2011.09. 002

Kiryu-Seo, S., Ohno, N., Kidd, G. J., Komuro, H., and Trapp, B. D. (2010). Demyelination increases axonal stationary mitochondrial size and the speed of axonal mitochondrial transport. J. Neurosci. 30, 6658-6666. doi: 10.1523/ JNEUROSCI.5265-09.2010

Klugmann, M., Schwab, M. H., Puhlhofer, A., Schneider, A., Zimmermann, F., Griffiths, I. R., et al. (1997). Assembly of CNS myelin in the absence of proteolipid protein. Neuron 18, 59-70. doi: 10.1016/S0896-6273(01)80046-5

Koenning, M., Jackson, S., Hay, C. M., Faux, C., Kilpatrick, T. J., Willingham, M., et al. (2012). Myelin gene regulatory factor is required for maintenance of myelin and mature oligodendrocyte identity in the adult CNS. J. Neurosci. 32, 12528-12542. doi: 10.1523/JNEUROSCI.1069-12.2012

Kohler, W., Curiel, J., and Vanderver, A. (2018). Adulthood leukodystrophies. Nat. Rev. Neurol. 14, 94-105. doi: 10.1038/nrneurol.2017.175

Koles, Z. J., and Rasminsky, M. (1972). A computer simulation of conduction in demyelinated nerve fibres. J. Physiol. 227, 351-364. doi: 10.1113/jphysiol.1972. sp010036

Komada, M., and Soriano, P. (2002). [Beta]IV-spectrin regulates sodium channel clustering through ankyrin-G at axon initial segments and nodes of Ranvier. J. Cell Biol. 156, 337-348. doi: 10.1083/jcb.200110003

Kornek, B., Storch, M. K., Bauer, J., Djamshidian, A., Weissert, R., Wallstroem, E., et al. (2001). Distribution of a calcium channel subunit in dystrophic axons in multiple sclerosis and experimental autoimmune encephalomyelitis. Brain 124, 1114-1124. doi: 10.1093/brain/124.6.1114

Kornek, B., Storch, M. K., Weissert, R., Wallstroem, E., Stefferl, A., Olsson, T., et al. (2000). Multiple sclerosis and chronic autoimmune encephalomyelitis: a comparative quantitative study of axonal injury in active, inactive, and remyelinated lesions. Am. J. Pathol. 157, 267-276. doi: 10.1016/S0002-9440(10) 64537-3

Kramer-Albers, E. M., Bretz, N., Tenzer, S., Winterstein, C., Mobius, W., Berger, H., et al. (2007). Oligodendrocytes secrete exosomes containing major myelin and stress-protective proteins: trophic support for axons? Proteomics Clin. Appl. 1, 1446-1461. doi: 10.1002/prca.200700522

Kuhlmann, T., Lingfeld, G., Bitsch, A., Schuchardt, J., and Bruck, W. (2002). Acute axonal damage in multiple sclerosis is most extensive in early disease stages and decreases over time. Brain 125, 2202-2212. doi: 10.1093/brain/awf235

Kurita, H., Kawahara, N., Asai, A., Ueki, K., Shin, M., and Kirino, T. (2001). Radiation-induced apoptosis of oligodendrocytes in the adult rat brain. Neurol. Res. 23, 869-874. doi: 10.1179/016164101101199324

Lappe-Siefke, C., Goebbels, S., Gravel, M., Nicksch, E., Lee, J., Braun, P. E., et al. (2003). Disruption of Cnp1 uncouples oligodendroglial functions in axonal support and myelination. Nat. Genet. 33, 366-374. doi: 10.1038/ ng1095

Larson, V. A., Mironova, Y., Vanderpool, K. G., Waisman, A., Rash, J. E., Agarwal, A., et al. (2018). Oligodendrocytes control potassium accumulation in white matter and seizure susceptibility. eLife 7:e34829. doi: 10.7554/eLife. 34829

Lasiene, J., Matsui, A., Sawa, Y., Wong, F., and Horner, P. J. (2009). Agerelated myelin dynamics revealed by increased oligodendrogenesis and short internodes. Aging Cell 8, 201-213. doi: 10.1111/j.1474-9726.2009.00462.x

Lasiene, J., Shupe, L., Perlmutter, S., and Horner, P. (2008). No evidence for chronic demyelination in spared axons after spinal cord injury in a mouse. J. Neurosci. 28, 3887-3896. doi: 10.1523/JNEUROSCI.4756-07.2008

Lassmann, H., and Bradl, M. (2017). Multiple sclerosis: experimental models and reality. Acta Neuropathol. 133, 223-244. doi: 10.1007/s00401-016-1631-4

Lassmann, H., Van Horssen, J., and Mahad, D. (2012). Progressive multiple sclerosis: pathology and pathogenesis. Nat. Rev. Neurol. 8, 647-656. doi: 10. 1038/nrneurol.2012.168

Laukka, J. J., Kamholz, J., Bessert, D., and Skoff, R. P. (2016). Novel pathologic findings in patients with pelizaeus-merzbacher disease. Neurosci. Lett. 627, 222-232. doi: 10.1016/j.neulet.2016.05.028

Le Pichon, C. E., Meilandt, W. J., Dominguez, S., Solanoy, H., Lin, H., Ngu, H., et al. (2017). Loss of dual leucine zipper kinase signaling is protective in animal models of neurodegenerative disease. Sci. Transl. Med. 9:eaag0394. doi: 10.1126/scitranslmed.aag0394 
Lee, Y., Morrison, B. M., Li, Y., Lengacher, S., Farah, M. H., Hoffman, P. N., et al. (2012). Oligodendroglia metabolically support axons and contribute to neurodegeneration. Nature 487, 443-448. doi: 10.1038/nature11314

Lennie, P. (2003). The cost of cortical computation. Curr. Biol. 13, 493-497. doi: 10.1016/S0960-9822(03)00135-0

Levite, M. (2017). Glutamate, T cells and multiple sclerosis. J. Neural Transm. 124, 775-798. doi: 10.1007/s00702-016-1661-z

Licht-Mayer, S., Campbell, G. R., Canizares, M., Mehta, A. R., Gane, A. B., Mcgill, K., et al. (2020). Enhanced axonal response of mitochondria to demyelination offers neuroprotection: implications for multiple sclerosis. Acta Neuropathol. 140, 143-167. doi: 10.1007/s00401-020-02179-x

Lin, M. Y., Cheng, X. T., Tammineni, P., Xie, Y., Zhou, B., Cai, Q., et al. (2017). Releasing syntaphilin removes stressed mitochondria from axons independent of mitophagy under pathophysiological conditions. Neuron 94, 595.e6-610.e6. doi: 10.1016/j.neuron.2017.04.004

Lindner, M., Fokuhl, J., Linsmeier, F., Trebst, C., and Stangel, M. (2009). Chronic toxic demyelination in the central nervous system leads to axonal damage despite remyelination. Neurosci. Lett. 453, 120-125. doi: 10.1016/j.neulet.2009. 02.004

Litsky, M. L., and Pfeiffer, D. R. (1997). Regulation of the mitochondrial Ca2+ uniporter by external adenine nucleotides: the uniporter behaves like a gated channel which is regulated by nucleotides and divalent cations. Biochemistry 36, 7071-7080. doi: 10.1021/bi970180y

Liu, J. S., Zhao, M. L., Brosnan, C. F., and Lee, S. C. (2001). Expression of inducible nitric oxide synthase and nitrotyrosine in multiple sclerosis lesions. Am. J. Pathol. 158, 2057-2066. doi: 10.1016/S0002-9440(10)64677-9

Llobet Rosell, A., and Neukomm, L. J. (2019). Axon death signalling in Wallerian degeneration among species and in disease. Open Biol. 9:190118. doi: 10.1098/ rsob. 190118

Lo, A. C., Saab, C. Y., Black, J. A., and Waxman, S. G. (2003). Phenytoin protects spinal cord axons and preserves axonal conduction and neurological function in a model of neuroinflammation in vivo. J. Neurophysiol. 90, 3566-3571. doi: 10.1152/jn.00434.2003

Looser, Z. J., Barrett, M. J. P., Hirrlinger, J., Weber, B., and Saab, A. S. (2018). Intravitreal AAV-delivery of genetically encoded sensors enabling simultaneous two-photon imaging and electrophysiology of optic nerve axons. Front. Cell Neurosci. 12:377. doi: 10.3389/fncel.2018.00377

Lovas, G., Nielsen, J. A., Johnson, K. R., and Hudson, L. D. (2010). Alterations in neuronal gene expression profiles in response to experimental demyelination and axonal transection. Mult. Scler. 16, 303-316. doi: 10.1177/ 1352458509357063

Lu, F., Selak, M., O'connor, J., Croul, S., Lorenzana, C., Butunoi, C., et al. (2000). Oxidative damage to mitochondrial DNA and activity of mitochondrial enzymes in chronic active lesions of multiple sclerosis. J. Neurol. Sci. 177, 95-103. doi: 10.1016/S0022-510X(00)00343-9

Lubetzki, C., Sol-Foulon, N., and Desmazieres, A. (2020a). Nodes of Ranvier during development and repair in the CNS. Nat. Rev. Neurol. 16, 426-439. doi: 10.1038/s41582-020-0375-x

Lubetzki, C., Zalc, B., Williams, A., Stadelmann, C., and Stankoff, B. (2020b). Remyelination in multiple sclerosis: from basic science to clinical translation. Lancet Neurol. 19, 678-688. doi: 10.1016/S1474-4422(20)30140-X

Lubinska, L. (1982). Patterns of Wallerian degeneration of myelinated fibres in short and long peripheral stumps and in isolated segments of rat phrenic nerve. Interpretation of the role of axoplasmic flow of the trophic factor. Brain Res. 233, 227-240. doi: 10.1016/0006-8993(82)91199-4

Luders, K. A., Nessler, S., Kusch, K., Patzig, J., Jung, R. B., Mobius, W., et al. (2019). Maintenance of high proteolipid protein level in adult central nervous system myelin is required to preserve the integrity of myelin and axons. Glia 67, 634-649. doi: 10.1002/glia.23549

Luders, K. A., Patzig, J., Simons, M., Nave, K. A., and Werner, H. B. (2017). Genetic dissection of oligodendroglial and neuronal Plp1 function in a novel mouse model of spastic paraplegia type 2. Glia 65 , 1762-1776. doi: 10.1002/glia. 23193

Lunn, E. R., Perry, V. H., Brown, M. C., Rosen, H., and Gordon, S. (1989). Absence of wallerian degeneration does not hinder regeneration in peripheral nerve. Eur. J. Neurosci. 1, 27-33. doi: 10.1111/j.1460-9568.1989.tb0 0771.x
Magnotti, L. M., Goodenough, D. A., and Paul, D. L. (2011). Functional heterotypic interactions between astrocyte and oligodendrocyte connexins. Glia 59, 26-34. doi: $10.1002 /$ glia. 21073

Mahad, D., Ziabreva, I., Lassmann, H., and Turnbull, D. (2008). Mitochondrial defects in acute multiple sclerosis lesions. Brain 131, 1722-1735. doi: 10.1093/ brain/awn105

Mandal, A., and Drerup, C. M. (2019). Axonal transport and mitochondrial function in neurons. Front. Cell Neurosci. 13:373. doi: 10.3389/fncel.2019. 00373

Manrique-Hoyos, N., Jurgens, T., Gronborg, M., Kreutzfeldt, M., Schedensack, M., Kuhlmann, T., et al. (2012). Late motor decline after accomplished remyelination: impact for progressive multiple sclerosis. Ann. Neurol. 71, 227244. doi: 10.1002/ana.22681

Marik, C., Felts, P. A., Bauer, J., Lassmann, H., and Smith, K. J. (2007). Lesion genesis in a subset of patients with multiple sclerosis: a role for innate immunity? Brain 130, 2800-2815. doi: 10.1093/brain/awm236

Marion, C. M., Radomski, K. L., Cramer, N. P., Galdzicki, Z., and Armstrong, R. C. (2018). Experimental traumatic brain injury identifies distinct early and late phase axonal conduction deficits of white matter pathophysiology, and reveals intervening recovery. J. Neurosci. 38, 8723-8736. doi: 10.1523/JNEUROSCI. 0819-18.2018

Mathis, C., Denisenko-Nehrbass, N., Girault, J. A., and Borrelli, E. (2001). Essential role of oligodendrocytes in the formation and maintenance of central nervous system nodal regions. Development 128, 4881-4890.

Mathys, H., Davila-Velderrain, J., Peng, Z., Gao, F., Mohammadi, S., Young, J. Z., et al. (2019). Single-cell transcriptomic analysis of Alzheimer's disease. Nature 570, 332-337. doi: 10.1038/s41586-019-1195-2

Matsushima, G. K., and Morell, P. (2001). The neurotoxicant, cuprizone, as a model to study demyelination and remyelination in the central nervous system. Brain Pathol. 11, 107-116. doi: 10.1111/j.1750-3639.2001.tb00385.x

McGuinness, M. C., Lu, J. F., Zhang, H. P., Dong, G. X., Heinzer, A. K., Watkins, P. A., et al. (2003). Role of ALDP (ABCD1) and mitochondria in X-linked adrenoleukodystrophy. Mol. Cell. Biol. 23, 744-753. doi: 10.1128/MCB.23.2. 744-753.2003

McKenzie, I. A., Ohayon, D., Li, H., De Faria, J. P., Emery, B., Tohyama, K., et al. (2014). Motor skill learning requires active central myelination. Science 346, 318-322. doi: 10.1126/science. 1254960

Medana, I., Martinic, M. A., Wekerle, H., and Neumann, H. (2001). Transection of major histocompatibility complex class I-induced neurites by cytotoxic $\mathrm{T}$ lymphocytes. Am. J. Pathol. 159, 809-815. doi: 10.1016/S0002-9440(10)61755-5

Mei, F., Lehmann-Horn, K., Shen, Y. A., Rankin, K. A., Stebbins, K. J., Lorrain, D. S., et al. (2016). Accelerated remyelination during inflammatory demyelination prevents axonal loss and improves functional recovery. eLife 5:e18246. doi: 10.7554/eLife.18246

Mendel, I., Kerlero, De Rosbo, N., and Ben-Nun, A. (1995). A myelin oligodendrocyte glycoprotein peptide induces typical chronic experimental autoimmune encephalomyelitis in H-2b mice: fine specificity and T cell receptor $\mathrm{V}$ beta expression of encephalitogenic T cells. Eur. J. Immunol. 25, 1951-1959. doi: 10.1002/eji.1830250723

Menichella, D. M., Goodenough, D. A., Sirkowski, E., Scherer, S. S., and Paul, D. L. (2003). Connexins are critical for normal myelination in the CNS. J. Neurosci. 23, 5963-5973. doi: 10.1523/JNEUROSCI.23-13-05963.2003

Meyer, N., Richter, N., Fan, Z., Siemonsmeier, G., Pivneva, T., Jordan, P., et al. (2018). Oligodendrocytes in the Mouse Corpus Callosum Maintain Axonal Function by Delivery of Glucose. Cell Rep. 22, 2383-2394. doi: 10.1016/j.celrep. 2018.02.022

Micu, I., Plemel, J. R., Caprariello, A. V., Nave, K. A., and Stys, P. K. (2017). Axo-myelinic neurotransmission: a novel mode of cell signalling in the central nervous system. Nat. Rev. Neurosci. 19, 49-58. doi: 10.1038/nrn.2017.128

Micu, I., Plemel, J. R., Lachance, C., Proft, J., Jansen, A. J., Cummins, K., et al. (2016). The molecular physiology of the axo-myelinic synapse. Exp. Neurol. 276, 41-50. doi: 10.1016/j.expneurol.2015.10.006

Mierzwa, A., Shroff, S., and Rosenbluth, J. (2010). Permeability of the paranodal junction of myelinated nerve fibers. J. Neurosci. 30, 15962-15968. doi: 10.1523/ JNEUROSCI.4047-10.2010

Miller, B. R., Press, C., Daniels, R. W., Sasaki, Y., Milbrandt, J., and Diantonio, A. (2009). A dual leucine kinase-dependent axon self-destruction program 
promotes Wallerian degeneration. Nat. Neurosci. 12, 387-389. doi: 10.1038/nn. 2290

Mimault, C., Giraud, G., Courtois, V., Cailloux, F., Boire, J. Y., Dastugue, B., et al. (1999). Proteolipoprotein gene analysis in 82 patients with sporadic PelizaeusMerzbacher Disease: duplications, the major cause of the disease, originate more frequently in male germ cells, but point mutations do not. The clinical european network on brain dysmyelinating disease. Am. J. Hum. Genet. 65, 360-369. doi: 10.1086/302483

Misgeld, T., Kerschensteiner, M., Bareyre, F. M., Burgess, R. W., and Lichtman, J. W. (2007). Imaging axonal transport of mitochondria in vivo. Nat. Methods 4, 559-561. doi: 10.1038/nmeth 1055

Misgeld, T., and Schwarz, T. L. (2017). Mitostasis in neurons: maintaining mitochondria in an extended cellular architecture. Neuron 96, 651-666. doi: 10.1016/j.neuron.2017.09.055

Morsali, D., Bechtold, D., Lee, W., Chauhdry, S., Palchaudhuri, U., Hassoon, P., et al. (2013). Safinamide and flecainide protect axons and reduce microglial activation in models of multiple sclerosis. Brain 136, 1067-1082. doi: 10.1093/ brain/awt041

Mosser, J., Douar, A.-M., Sarde, C.-O., Kioschis, P., Feil, R., Moser, H., et al. (1993). Putative X-linked adrenoleukodystrophy gene shares unexpected homology with ABC transporters. Nature 361, 726-730. doi: 10.1038/361726a0

Mukherjee, C., Kling, T., Russo, B., Miebach, K., Kess, E., Schifferer, M., et al. (2020). Oligodendrocytes provide antioxidant defense function for neurons by secreting ferritin heavy chain. Cell Metab. 32, 259.e10-272.e10. doi: 10.1016/j. cmet.2020.05.019

Mutsaers, S. E., and Carroll, W. M. (1998). Focal accumulation of intra-axonal mitochondria in demyelination of the cat optic nerve. Acta Neuropathol. 96, 139-143. doi: 10.1007/s004010050873

Nasrabady, S. E., Rizvi, B., Goldman, J. E., and Brickman, A. M. (2018). White matter changes in Alzheimer's disease: a focus on myelin and oligodendrocytes. Acta Neuropathol. Commun. 6:22. doi: 10.1186/s40478-018-0515-3

Nave, K. A. (2010). Myelination and the trophic support of long axons. Nat. Rev. Neurosci. 11, 275-283. doi: 10.1038/nrn2797

Nave, K. A., and Trapp, B. D. (2008). Axon-glial signaling and the glial support of axon function. Annu. Rev. Neurosci. 31, 535-561. doi: 10.1146/annurev.neuro. 30.051606.094309

Nichols, M., Elustondo, P. A., Warford, J., Thirumaran, A., Pavlov, E. V., and Robertson, G. S. (2017). Global ablation of the mitochondrial calcium uniporter increases glycolysis in cortical neurons subjected to energetic stressors. J. Cereb. Blood Flow Metab. 37, 3027-3041. doi: 10.1177/0271678X16682250

Nicolli, A., Basso, E., Petronilli, V., Wenger, R. M., and Bernardi, P. (1996). Interactions of cyclophilin with the mitochondrial inner membrane and regulation of the permeability transition pore, and cyclosporin A-sensitive channel. J. Biol. Chem. 271, 2185-2192. doi: 10.1074/jbc.271.4.2185

Nikic, I., Merkler, D., Sorbara, C., Brinkoetter, M., Kreutzfeldt, M., Bareyre, F. M., et al. (2011). A reversible form of axon damage in experimental autoimmune encephalomyelitis and multiple sclerosis. Nat. Med. 17, 495-499. doi: 10.1038/ nm.2324

Niu, J., Li, T., Yi, C., Huang, N., Koulakoff, A., Weng, C., et al. (2016). Connexinbased channels contribute to metabolic pathways in the oligodendroglial lineage. J. Cell Sci. 129, 1902-1914. doi: 10.1242/jcs.178731

Ohno, N., Chiang, H., Mahad, D. J., Kidd, G. J., Liu, L., Ransohoff, R. M., et al. (2014). Mitochondrial immobilization mediated by syntaphilin facilitates survival of demyelinated axons. Proc. Natl. Acad. Sci. U.S.A. 111, 9953-9958. doi: 10.1073/pnas.1401155111

Ohno, N., Kidd, G. J., Mahad, D., Kiryu-Seo, S., Avishai, A., Komuro, H., et al. (2011). Myelination and axonal electrical activity modulate the distribution and motility of mitochondria at CNS nodes of Ranvier. J. Neurosci. 31, 7249-7258. doi: 10.1523/JNEUROSCI.0095-11.2011

Oleszak, E. L., Zaczynska, E., Bhattacharjee, M., Butunoi, C., Legido, A., and Katsetos, C. D. (1998). Inducible nitric oxide synthase and nitrotyrosine are found in monocytes/macrophages and/or astrocytes in acute, but not in chronic, multiple sclerosis. Clin. Diagn. Lab. Immunol. 5, 438-445. doi: 10.1128/ CDLI.5.4.438-445.1998

Oluich, L. J., Stratton, J. A., Xing, Y. L., Ng, S. W., Cate, H. S., Sah, P., et al. (2012). Targeted ablation of oligodendrocytes induces axonal pathology independent of overt demyelination. J. Neurosci. 32, 8317-8330. doi: 10.1523/JNEUROSCI. 1053- 12.2012
Orthmann-Murphy, J., Call, C. L., Molina-Castro, G. C., Hsieh, Y. C., Rasband, M. N., Calabresi, P. A., et al. (2020). Remyelination alters the pattern of myelin in the cerebral cortex. eLife 9:e56621. doi: 10.7554/eLife.56621

Orthmann-Murphy, J. L., Freidin, M., Fischer, E., Scherer, S. S., and Abrams, C. K. (2007). Two distinct heterotypic channels mediate gap junction coupling between astrocyte and oligodendrocyte connexins. J. Neurosci. 27, 1394913957. doi: 10.1523/JNEUROSCI.3395-07.2007

Osterloh, J. M., Yang, J., Rooney, T. M., Fox, A. N., Adalbert, R., Powell, E. H., et al. (2012). dSarm/Sarm 1 is required for activation of an injury-induced axon death pathway. Science 337, 481-484. doi: 10.1126/science.1223899

Ouardouz, M., Coderre, E., Basak, A., Chen, A., Zamponi, G. W., Hameed, S., et al. (2009). Glutamate receptors on myelinated spinal cord axons: I. GluR6 kainate receptors. Ann. Neurol. 65, 151-159. doi: 10.1002/ana.21533

Ouardouz, M., Nikolaeva, M. A., Coderre, E., Zamponi, G. W., Mcrory, J. E., Trapp, B. D., et al. (2003). Depolarization-induced Ca2+ release in ischemic spinal cord white matter involves L-type $\mathrm{Ca} 2+$ channel activation of ryanodine receptors. Neuron 40, 53-63. doi: 10.1016/j.neuron.2003.08.016

Pacher, P., Beckman, J. S., and Liaudet, L. (2007). Nitric oxide and peroxynitrite in health and disease. Physiol. Rev. 87, 315-424. doi: 10.1152/physrev.00029. 2006

Pampliega, O., Domercq, M., Soria, F. N., Villoslada, P., Rodriguez-Antiguedad, A., and Matute, C. (2011). Increased expression of cystine/glutamate antiporter in multiple sclerosis. J. Neuroinflammation 8:63. doi: 10.1186/1742-2094-8-63

Pan, S., Mayoral, S. R., Choi, H. S., Chan, J. R., and Kheirbek, M. A. (2020). Preservation of a remote fear memory requires new myelin formation. Nat. Neurosci. 23, 487-499. doi: 10.1038/s41593-019-0582-1

Papadopoulos, D., Pham-Dinh, D., and Reynolds, R. (2006). Axon loss is responsible for chronic neurological deficit following inflammatory demyelination in the rat. Exp. Neurol. 197, 373-385. doi: 10.1016/j.expneurol. 2005.10.033

Patrikios, P., Stadelmann, C., Kutzelnigg, A., Rauschka, H., Schmidbauer, M., Laursen, H., et al. (2006). Remyelination is extensive in a subset of multiple sclerosis patients. Brain 129, 3165-3172. doi: 10.1093/brain/awl217

Pellerin, L., and Magistretti, P. J. (1994). Glutamate uptake into astrocytes stimulates aerobic glycolysis: a mechanism coupling neuronal activity to glucose utilization. Proc. Natl. Acad. Sci. U.S.A. 91, 10625-10629. doi: 10.1073/pnas.91. 22.10625

Pesini, P., Kopp, J., Wong, H., Walsh, J. H., Grant, G., and Hokfelt, T. (1999). An immunohistochemical marker for Wallerian degeneration of fibers in the central and peripheral nervous system. Brain Res. 828, 41-59. doi: 10.1016/ S0006-8993(99)01283-4

Philippot, C., Griemsmann, S., Jabs, R., Seifert, G., Kettenmann, H., and Steinhauser, C. (2021). Astrocytes and oligodendrocytes in the thalamus jointly maintain synaptic activity by supplying metabolites. Cell Rep. 34:108642. doi: 10.1016/j.celrep.2020.108642

Philips, T., Bento-Abreu, A., Nonneman, A., Haeck, W., Staats, K., Geelen, V., et al. (2013). Oligodendrocyte dysfunction in the pathogenesis of amyotrophic lateral sclerosis. Brain 136, 471-482. doi: 10.1093/brain/aws339

Philips, T., Mironova, Y. A., Jouroukhin, Y., Chew, J., Vidensky, S., Farah, M. H., et al. (2021). MCT1 deletion in oligodendrocyte lineage cells causes late-onset hypomyelination and axonal degeneration. Cell Rep. 34:108610. doi: 10.1016/j. celrep.2020.108610

Piao, J., Major, T., Auyeung, G., Policarpio, E., Menon, J., Droms, L., et al. (2015). Human embryonic stem cell-derived oligodendrocyte progenitors remyelinate the brain and rescue behavioral deficits following radiation. Cell Stem Cell 16, 198-210. doi: 10.1016/j.stem.2015.01.004

Pitt, D., Werner, P., and Raine, C. S. (2000). Glutamate excitotoxicity in a model of multiple sclerosis. Nat. Med. 6, 67-70. doi: 10.1038/71555

Plemel, J. R., Liu, W. Q., and Yong, V. W. (2017). Remyelination therapies: a new direction and challenge in multiple sclerosis. Nat. Rev. Drug Discov. 16, 617-634. doi: 10.1038/nrd.2017.115

Plemel, J. R., Michaels, N. J., Weishaupt, N., Caprariello, A. V., Keough, M. B., Rogers, J. A., et al. (2018). Mechanisms of lysophosphatidylcholine-induced demyelination: a primary lipid disrupting myelinopathy. Glia 66, 327-347. doi: 10.1002/glia.23245

Pohl, H. B. F., Porcheri, C., Mueggler, T., Bachmann, L. C., Martino, G., Riethmacher, D., et al. (2011). Genetically induced adult oligodendrocyte cell death is associated with poor myelin clearance, reduced remyelination, and 
axonal damage. J. Neurosci. 31, 1069-1080. doi: 10.1523/JNEUROSCI.5035-10. 2011

Poliak, S., Salomon, D., Elhanany, H., Sabanay, H., Kiernan, B., Pevny, L., et al. (2003). Juxtaparanodal clustering of Shaker-like K+ channels in myelinated axons depends on Caspr2 and TAG-1. J. Cell Biol. 162, 1149-1160. doi: 10.1083/ jcb. 200305018

Powers, J. M., Deciero, D. P., Ito, M., Moser, A. B., and Moser, H. W. (2000). Adrenomyeloneuropathy: a neuropathologic review featuring its noninflammatory myelopathy. J. Neuropathol. Exp. Neurol. 59, 89-102. doi: 10.1093/jnen/59.2.89

Raftopoulos, R., Hickman, S. J., Toosy, A., Sharrack, B., Mallik, S., Paling, D., et al. (2016). Phenytoin for neuroprotection in patients with acute optic neuritis: a randomised, placebo-controlled, phase 2 trial. Lancet Neurol. 15, 259-269. doi: 10.1016/S1474-4422(16)00004- 1

Ransohoff, R. M. (2012). Animal models of multiple sclerosis: the good, the bad and the bottom line. Nat. Neurosci. 15, 1074-1077. doi: 10.1038/nn.3168

Rasband, M. N., and Peles, E. (2015). The nodes of ranvier: molecular assembly and maintenance. Cold Spring Harb. Perspect. Biol. 8:a020495. doi: 10.1101/ cshperspect.a020495

Rasband, M. N., and Peles, E. (2021). Mechanisms of node of Ranvier assembly. Nat. Rev. Neurosci. 22, 7-20. doi: 10.1038/s41583-020-00406-8

Rasband, M. N., Peles, E., Trimmer, J. S., Levinson, S. R., Lux, S. E., and Shrager, P. (1999). Dependence of nodal sodium channel clustering on paranodal axoglial contact in the developing CNS. J. Neurosci. 19, 7516-7528. doi: 10.1523/ JNEUROSCI.19-17-07516.1999

Rasband, M. N., Trimmer, J. S., Schwarz, T. L., Levinson, S. R., Ellisman, M. H., Schachner, M., et al. (1998). Potassium channel distribution, clustering, and function in remyelinating rat axons. J. Neurosci. 18, 36-47. doi: 10.1523/ JNEUROSCI.18-01-00036.1998

Rash, J. E. (2010). Molecular disruptions of the panglial syncytium block potassium siphoning and axonal saltatory conduction: pertinence to neuromyelitis optica and other demyelinating diseases of the central nervous system. Neuroscience 168, 982-1008. doi: 10.1016/j.neuroscience.2009.10.028

Readhead, C., Schneider, A., Griffiths, I., and Nave, K. A. (1994). Premature arrest of myelin formation in transgenic mice with increased proteolipid protein gene dosage. Neuron 12, 583-595. doi: 10.1016/0896-6273(94)90214-3

Redford, E. J., Kapoor, R., and Smith, K. J. (1997). Nitric oxide donors reversibly block axonal conduction: demyelinated axons are especially susceptible. Brain 120(Pt 12), 2149-2157. doi: 10.1093/brain/120.12.2149

Rinholm, J. E., Hamilton, N. B., Kessaris, N., Richardson, W. D., Bergersen, L. H., and Attwell, D. (2011). Regulation of oligodendrocyte development and myelination by glucose and lactate. J. Neurosci. 31, 538-548. doi: 10.1523/ JNEUROSCI.3516-10.2011

Rios, J. C., Rubin, M., St Martin, M., Downey, R. T., Einheber, S., Rosenbluth, J., et al. (2003). Paranodal interactions regulate expression of sodium channel subtypes and provide a diffusion barrier for the node of Ranvier. J. Neurosci. 23, 7001-7011. doi: 10.1523/JNEUROSCI.23-18-07001.2003

Roots, B. I. (2008). The phylogeny of invertebrates and the evolution of myelin. Neuron Glia Biol. 4, 101-109. doi: 10.1017/S1740925X0900012X

Rosenbluth, J. (1980). Central myelin in the mouse mutant shiverer. J. Comp. Neurol. 194, 639-648. doi: 10.1002/cne.901940310

Rosenbluth, J., Stoffel, W., and Schiff, R. (1996). Myelin structure in proteolipid protein (PLP)-null mouse spinal cord. J. Comp. Neurol. 371, 336-344. doi: 10.1002/(SICI)1096-9861(19960722)371:2<336::AID-CNE12>3.0.CO;2-Q

Rosenzweig, S., and Carmichael, S. T. (2013). Age-dependent exacerbation of white matter stroke outcomes: a role for oxidative damage and inflammatory mediators. Stroke 44, 2579-2586. doi: 10.1161/STROKEAHA.113.00 1796

Saab, A. S., Tzvetavona, I. D., Trevisiol, A., Baltan, S., Dibaj, P., Kusch, K., et al. (2016). Oligodendroglial NMDA receptors regulate glucose import and axonal energy metabolism. Neuron 91, 119-132. doi: 10.1016/j.neuron.2016. 05.016

Sachs, H. H., Bercury, K. K., Popescu, D. C., Narayanan, S. P., and Macklin, W. B. (2014). A new model of cuprizone-mediated demyelination/remyelination. ASN Neuro 6:1759091414551955. doi: 10.1177/1759091414551955

Sadeghian, M., Mastrolia, V., Haddad, A. R., Mosley, A., Mullali, G., Schiza, D., et al. (2016). Mitochondrial dysfunction is an important cause of neurological deficits in an inflammatory model of multiple sclerosis. Sci. Rep. 6:33249. doi: $10.1038 /$ srep33249

Sathornsumetee, S., Mcgavern, D. B., Ure, D. R., and Rodriguez, M. (2000). Quantitative ultrastructural analysis of a single spinal cord demyelinated lesion predicts total lesion load, axonal loss, and neurological dysfunction in a murine model of multiple sclerosis. Am. J. Pathol. 157, 1365-1376. doi: 10.1016/S00029440(10)64650-0

Schirmer, L., Mobius, W., Zhao, C., Cruz-Herranz, A., Ben Haim, L., Cordano, C., et al. (2018). Oligodendrocyte-encoded Kir4.1 function is required for axonal integrity. eLife 7:e36428. doi: 10.7554/eLife.36428

Schirmer, L., Velmeshev, D., Holmqvist, S., Kaufmann, M., Werneburg, S., Jung, D., et al. (2019). Neuronal vulnerability and multilineage diversity in multiple sclerosis. Nature 573, 75-82. doi: 10.1038/s41586-019-1404-z

Schlaepfer, W. W., and Bunge, R. P. (1973). Effects of calcium ion concentration on the degeneration of amputated axons in tissue culture. J. Cell Biol. 59, 456-470. doi: $10.1083 /$ jcb.59.2.456

Schneider, S., Gruart, A., Grade, S., Zhang, Y., Kroger, S., Kirchhoff, F., et al. (2016). Decrease in newly generated oligodendrocytes leads to motor dysfunctions and changed myelin structures that can be rescued by transplanted cells. Glia 64, 2201-2218. doi: 10.1002/glia.23055

Schuh, C., Wimmer, I., Hametner, S., Haider, L., Van Dam, A. M., Liblau, R. S., et al. (2014). Oxidative tissue injury in multiple sclerosis is only partly reflected in experimental disease models. Acta Neuropathol. 128, 247-266. doi: 10.1007/ s00401-014-1263-5

Shields, D. C., Schaecher, K. E., Saido, T. C., and Banik, N. L. (1999). A putative mechanism of demyelination in multiple sclerosis by a proteolytic enzyme, calpain. Proc. Natl. Acad. Sci. U.S.A. 96, 11486-11491. doi: 10.1073/pnas.96.20. 11486

Shriver, L. P., and Dittel, B. N. (2006). T-cell-mediated disruption of the neuronal microtubule network: correlation with early reversible axonal dysfunction in acute experimental autoimmune encephalomyelitis. Am. J. Pathol. 169, 9991011. doi: 10.2353/ajpath.2006.050791

Simons, M., Kramer, E. M., Macchi, P., Rathke-Hartlieb, S., Trotter, J., Nave, K. A., et al. (2002). Overexpression of the myelin proteolipid protein leads to accumulation of cholesterol and proteolipid protein in endosomes/lysosomes: implications for Pelizaeus-Merzbacher disease. J. Cell Biol. 157, 327-336. doi: $10.1083 /$ jcb. 200110138

Simons, M., and Nave, K. A. (2016). Oligodendrocytes: myelination and axonal support. Cold Spring Harb. Perspect. Biol. 8:a020479. doi: 10.1101/cshperspect. a020479

Singh, S., Dallenga, T., Winkler, A., Roemer, S., Maruschak, B., Siebert, H., et al. (2017). Relationship of acute axonal damage, Wallerian degeneration, and clinical disability in multiple sclerosis. J. Neuroinflammation 14:57. doi: 10. 1186/s12974-017-0831-8

Skripuletz, T., Hackstette, D., Bauer, K., Gudi, V., Pul, R., Voss, E., et al. (2013). Astrocytes regulate myelin clearance through recruitment of microglia during cuprizone-induced demyelination. Brain 136, 147-167. doi: 10.1093/brain/ aws 262

Smith, A. W., Das, A., Guyton, M. K., Ray, S. K., Rohrer, B., and Banik, N. L. (2011). Calpain inhibition attenuates apoptosis of retinal ganglion cells in acute optic neuritis. Invest. Ophthalmol. Vis. Sci. 52, 4935-4941. doi: 10.1167/iovs. 10-7027

Smith, C. M., Cooksey, E., and Duncan, I. D. (2013). Myelin loss does not lead to axonal degeneration in a long-lived model of chronic demyelination. J. Neurosci. 33, 2718-2727. doi: 10.1523/JNEUROSCI.462712.2013

Smith, K. J., Blakemore, W. F., and McDonald, W. I. (1979). Central remyelination restores secure conduction. Nature 280, 395-396. doi: 10.1038/280395a0

Smith, K. J., Kapoor, R., Hall, S. M., and Davies, M. (2001). Electrically active axons degenerate when exposed to nitric oxide. Ann. Neurol. 49, 470-476. doi: 10.1002/ana.96

Smith, K. J., and McDonald, W. I. (1982). Spontaneous and evoked electrical discharges from a central demyelinating lesion. J. Neurol. Sci. 55, 39-47. doi: 10.1016/0022-510X(82)90168-X

Smith, T., Groom, A., Zhu, B., and Turski, L. (2000). Autoimmune encephalomyelitis ameliorated by AMPA antagonists. Nat. Med. 6, 62-66. doi: $10.1038 / 71548$ 
Snaidero, N., Mobus, W., Czopka, T., Hekking, L. H. P., Mathisen, C., Verkleij, D., et al. (2014). Myelin membrane wrapping of CNS axons by PI(3,4,5) P3dependent polarized growth at the inner tongue. Cell 156, 277-290. doi: 10. 1016/j.cell.2013.11.044

Snaidero, N., Velte, C., Myllykoski, M., Raasakka, A., Ignatev, A., Werner, H. B., et al. (2017). Antagonistic functions of MBP and CNP establish cytosolic channels in CNS myelin. Cell. Rep. 18, 314-323. doi: 10.1016/j.celrep.2016.12. 053

Sorbara, C. D., Wagner, N. E., Ladwig, A., Nikic, I., Merkler, D., Kleele, T., et al. (2014). Pervasive axonal transport deficits in multiple sclerosis models. Neuron 84, 1183-1190. doi: 10.1016/j.neuron.2014.11.006

Soulika, A. M., Lee, E., Mccauley, E., Miers, L., Bannerman, P., and Pleasure, D. (2009). Initiation and progression of axonopathy in experimental autoimmune encephalomyelitis. J. Neurosci. 29, 14965-14979. doi: 10.1523/JNEUROSCI. 3794-09.2009

Sozmen, E. G., Rosenzweig, S., Llorente, I. L., Ditullio, D. J., Machnicki, M., Vinters, H. V., et al. (2016). Nogo receptor blockade overcomes remyelination failure after white matter stroke and stimulates functional recovery in aged mice. Proc. Natl. Acad. Sci. U.S.A. 113, E8453-E8462. doi: 10.1073/pnas.161532 2113

Srinivasan, R., Cunningham, C., Chen, A., Vigneron, D., Hurd, R., Nelson, S., et al. (2006). TE-averaged two-dimensional proton spectroscopic imaging of glutamate at 3 T. Neuroimage 30, 1171-1178. doi: 10.1016/j.neuroimage.2005. 10.048

Stadelmann, C., Timmler, S., Barrantes-Freer, A., and Simons, M. (2019). Myelin in the central nervous system: structure, function, and pathology. Physiol. Rev. 99, 1381-1431. doi: 10.1152/physrev.00031.2018

Stangel, M., Kuhlmann, T., Matthews, P. M., and Kilpatrick, T. J. (2017). Achievements and obstacles of remyelinating therapies in multiple sclerosis. Nat. Rev. Neurol. 13, 742-754. doi: 10.1038/nrneurol.2017.139

Stassart, R. M., Mobius, W., Nave, K. A., and Edgar, J. M. (2018). The axonmyelin unit in development and degenerative disease. Front. Neurosci. 12:467. doi: 10.3389/fnins.2018.00467

Steadman, P. E., Xia, F., Ahmed, M., Mocle, A. J., Penning, A. R. A., Geraghty, A. C., et al. (2019). Disruption of oligodendrogenesis impairs memory consolidation in adult mice. Neuron 105, 150.e6-164.e6. doi: 10.1016/j.neuron.2019. 10.013

Stirling, D. P., Cummins, K., Wayne Chen, S. R., and Stys, P. (2014). Axoplasmic reticulum $\mathrm{Ca}(2+)$ release causes secondary degeneration of spinal axons. Ann. Neurol. 75, 220-229. doi: 10.1002/ana.24099

Stirling, D. P., and Stys, P. K. (2010). Mechanisms of axonal injury: internodal nanocomplexes and calcium deregulation. Trends Mol. Med. 16, 160-170. doi: 10.1016/j.molmed.2010.02.002

Stys, P. K., Waxman, S. G., and Ransom, B. R. (1991). Reverse operation of the $\mathrm{Na}(+)-\mathrm{Ca} 2+$ exchanger mediates $\mathrm{Ca} 2+$ influx during anoxia in mammalian CNS white matter. Ann. N. Y. Acad. Sci. 639, 328-332. doi: 10.1111/j.1749-6632. 1991.tb17321.x

Stys, P. K., Waxman, S. G., and Ransom, B. R. (1992). Ionic mechanisms of anoxic injury in mammalian CNS white matter: role of $\mathrm{Na}+$ channels and $\mathrm{Na}(+)-\mathrm{Ca} 2+$ exchanger. J. Neurosci. 12, 430-439. doi: 10.1523/JNEUROSCI.12-02-00430. 1992

Sulkowski, G., Dabrowska-Bouta, B., Chalimoniuk, M., and Struzynska, L. (2013). Effects of antagonists of glutamate receptors on pro-inflammatory cytokines in the brain cortex of rats subjected to experimental autoimmune encephalomyelitis. J. Neuroimmunol. 261, 67-76. doi: 10.1016/j.jneuroim.2013. 05.006

Summers, D. W., Frey, E., Walker, L. J., Milbrandt, J., and Diantonio, A. (2020). DLK activation synergizes with mitochondrial dysfunction to downregulate axon survival factors and promote SARM1-dependent axon degeneration. Mol. Neurobiol. 57, 1146-1158. doi: 10.1007/s12035-019-01796-2

Summers, D. W., Milbrandt, J., and Diantonio, A. (2018). Palmitoylation enables MAPK-dependent proteostasis of axon survival factors. Proc. Natl. Acad. Sci. U.S.A. 115, E8746-E8754. doi: 10.1073/pnas.1806933115

Susuki, K., Chang, K. J., Zollinger, D. R., Liu, Y., Ogawa, Y., Eshed-Eisenbach, Y., et al. (2013). Three mechanisms assemble central nervous system nodes of Ranvier. Neuron 78, 469-482. doi: 10.1016/j.neuron.2013.03.005

Suzuki, K. (1969). Giant hepatic mitochondria: production in mice fed with cuprizone. Science 163, 81-82. doi: 10.1126/science.163.3862.81
Suzuki, K., and Kikkawa, Y. (1969). Status spongiosus of CNS and hepatic changes induced by cuprizone (biscyclohexanone oxalyldihydrazone). Am. J. Pathol. 54, 307-325.

Tekkok, S. B., Brown, A. M., Westenbroek, R., Pellerin, L., and Ransom, B. R. (2005). Transfer of glycogen-derived lactate from astrocytes to axons via specific monocarboxylate transporters supports mouse optic nerve activity. J. Neurosci. Res. 81, 644-652.

Thetiot, M., Freeman, S. A., Roux, T., Dubessy, A. L., Aigrot, M. S., Rappeneau, Q., et al. (2020). An alternative mechanism of early nodal clustering and myelination onset in GABAergic neurons of the central nervous system. Glia 68, 1891-1909.

Tokuhara, N., Namiki, K., Uesugi, M., Miyamoto, C., Ohgoh, M., Ido, K., et al. (2010). N-type calcium channel in the pathogenesis of experimental autoimmune encephalomyelitis. J. Biol. Chem. 285, 33294-33306.

Traka, M., Arasi, K., Avila, R. L., Podojil, J. R., Christakos, A., Miller, S. D., et al. (2010). A genetic mouse model of adult-onset, pervasive central nervous system demyelination with robust remyelination. Brain 133, 3017-3029.

Traka, M., Goutebroze, L., Denisenko, N., Bessa, M., Nifli, A., Havaki, S., et al. (2003). Association of TAG-1 with Caspr2 is essential for the molecular organization of juxtaparanodal regions of myelinated fibers. J. Cell Biol. 162, $1161-1172$.

Trapp, B. D., Bernier, L., Andrews, S. B., and Colman, D. R. (1988). Cellular and subcellular distribution of 2',3'-cyclic nucleotide 3'-phosphodiesterase and its mRNA in the rat central nervous system. J. Neurochem. 51, 859-868.

Trapp, B. D., and Nave, K. A. (2008). Multiple sclerosis: an immune or neurodegenerative disorder? Annu. Rev. Neurosci. 31, 247-269.

Trapp, B. D., and Stys, P. K. (2009). Virtual hypoxia and chronic necrosis of demyelinated axons in multiple sclerosis. Lancet Neurol. 8, 280-291.

Trevisiol, A., Saab, A. S., Winkler, U., Marx, G., Imamura, H., Mobius, W., et al. (2017). Monitoring ATP dynamics in electrically active white matter tracts. eLife 6:e24241.

Tullius, S. G., Biefer, H. R., Li, S., Trachtenberg, A. J., Edtinger, K., Quante, M., et al. (2014). NAD+ protects against EAE by regulating CD4+ T-cell differentiation. Nat. Commun. 5:5101.

van den Berg, R., Hoogenraad, C. C., and Hintzen, R. Q. (2017). Axonal transport deficits in multiple sclerosis: spiraling into the abyss. Acta Neuropathol. 134, $1-14$.

van der Knaap, M. S., Schiffmann, R., Mochel, F., and Wolf, N. I. (2019). Diagnosis, prognosis, and treatment of leukodystrophies. Lancet Neurol. 18, 962-972.

van Roermund, C. W., Visser, W. F., Ijlst, L., Waterham, H. R., and Wanders, R. J. (2011). Differential substrate specificities of human ABCD1 and ABCD2 in peroxisomal fatty acid beta-oxidation. Biochim. Biophys. Acta 1811, 148-152.

Velumian, A. A., Samoilova, M., and Fehlings, M. G. (2011). Visualization of cytoplasmic diffusion within living myelin sheaths of CNS white matter axons using microinjection of the fluorescent dye Lucifer yellow. Neuroimage 56, $27-34$.

Viar, K., Njoku, D., Secor Mcvoy, J., and Oh, U. (2020). Sarm1 knockout protects against early but not late axonal degeneration in experimental allergic encephalomyelitis. PLoS One 15:e0235110. doi: 10.1371/journal.pone.0235110

Villegas, R., Martinez, N. W., Lillo, J., Pihan, P., Hernandez, D., Twiss, J. L., et al. (2014). Calcium release from intra-axonal endoplasmic reticulum leads to axon degeneration through mitochondrial dysfunction. J. Neurosci. 34, 7179-7189.

Volkenhoff, A., Weiler, A., Letzel, M., Stehling, M., Klambt, C., and Schirmeier, S. (2015). Glial glycolysis is essential for neuronal survival in Drosophila. Cell Metab. 22, 437-447.

Walker, L. J., Summers, D. W., Sasaki, Y., Brace, E. J., Milbrandt, J., and Diantonio, A. (2017). MAPK signaling promotes axonal degeneration by speeding the turnover of the axonal maintenance factor NMNAT2. eLife 6: e22540.

Waller, A. (1851). Experiments on the section of the glosso-pharyngeal and hypoglossal nerves of the frog, and observations of the alterations produced thereby in the structure of their primitive fibres. Edinb. Med. Surg. J. 76, 369-376.

Wan, R., Cheli, V. T., Santiago-Gonzalez, D. A., Rosenblum, S. L., Wan, Q., and Paez, P. M. (2020). Impaired postnatal myelination in a conditional knockout mouse for the ferritin heavy chain in oligodendroglial cells. J. Neurosci. 40, $7609-7624$. 
Wang, H., Kunkel, D. D., Martin, T. M., Schwartzkroin, P. A., and Tempel, B. L. (1993). Heteromultimeric $\mathrm{K}+$ channels in terminal and juxtaparanodal regions of neurons. Nature 365, 75-79.

Wang, J. T., Medress, Z. A., and Barres, B. A. (2012). Axon degeneration: molecular mechanisms of a self-destruction pathway. J. Cell Biol. 196, 7-18.

Warne, J., Pryce, G., Hill, J. M., Shi, X., Lenneras, F., Puentes, F., et al. (2016). Selective inhibition of the mitochondrial permeability transition pore protects against neurodegeneration in experimental multiple sclerosis. J. Biol. Chem. 291, 4356-4373.

Waxman, S. G., and Bennett, M. V. (1972). Relative conduction velocities of small myelinated and non-myelinated fibres in the central nervous system. Nat. New Biol. 238, 217-219.

Waxman, S. G., and Brill, M. H. (1978). Conduction through Demyelinated Plaques in Multiple-Sclerosis - Computer Simulations of Facilitation by Short Internodes. J. Neurol. Neurosurg. Psychiatry 41, 408-416.

Wei, J., Guo, H., and Kuo, P. C. (2002). Endotoxin-stimulated nitric oxide production inhibits expression of cytochrome $c$ oxidase in ANA-1 murine macrophages. J. Immunol. 168, 4721-4727.

Werneburg, S., Jung, J., Kunjamma, R. B., Ha, S. K., Luciano, N. J., Willis, C. M., et al. (2020). Targeted complement inhibition at synapses prevents microglial synaptic engulfment and synapse loss in demyelinating disease. Immunity 52, 167.e7-182.e7.

Wiesinger, C., Kunze, M., Regelsberger, G., Forss-Petter, S., and Berger, J. (2013). Impaired very long-chain acyl-CoA beta-oxidation in human X-linked adrenoleukodystrophy fibroblasts is a direct consequence of ABCD1 transporter dysfunction. J. Biol. Chem. 288, 19269-19279.

Witte, M. E., Schumacher, A. M., Mahler, C. F., Bewersdorf, J. P., Lehmitz, J., Scheiter, A., et al. (2019). Calcium influx through plasma-membrane nanoruptures drives axon degeneration in a model of multiple sclerosis. Neuron 101, 615.e5-624.e5.

Wolf, N. I., Ffrench-Constant, C., and Van Der Knaap, M. S. (2020). Hypomyelinating leukodystrophies - unravelling myelin biology. Nat. Rev. Neurol. 17, 88-103.

Wolswijk, G., and Balesar, R. (2003). Changes in the expression and localization of the paranodal protein Caspr on axons in chronic multiple sclerosis. Brain 126, 1638-1649.

Woodruff, R. H., and Franklin, R. J. (1999). Demyelination and remyelination of the caudal cerebellar peduncle of adult rats following stereotaxic injections of lysolecithin, ethidium bromide, and complement/anti-galactocerebroside: a comparative study. Glia 25, 216-228.

Wujek, J. R., Bjartmar, C., Richer, E., Ransohoff, R. M., Yu, M., Tuohy, V. K., et al. (2002). Axon loss in the spinal cord determines permanent neurological disability in an animal model of multiple sclerosis. J. Neuropathol. Exp. Neurol. $61,23-32$.

Xiao, L., Ohayon, D., McKenzie, I. A., Sinclair-Wilson, A., Wright, J. L., Fudge, A. D., et al. (2016). Rapid production of new oligodendrocytes is required in the earliest stages of motor-skill learning. Nat. Neurosci. 19, 1210-1217.

Yakes, F. M., and Van Houten, B. (1997). Mitochondrial DNA damage is more extensive and persists longer than nuclear DNA damage in human cells following oxidative stress. Proc. Natl. Acad. Sci. U.S.A. 94, 514-519.
Yan, S. S., Wu, Z. Y., Zhang, H. P., Furtado, G., Chen, X., Yan, S. F., et al. (2003). Suppression of experimental autoimmune encephalomyelitis by selective blockade of encephalitogenic T-cell infiltration of the central nervous system. Nat. Med. 9, 287-293.

Yang, J., Weimer, R. M., Kallop, D., Olsen, O., Wu, Z., Renier, N., et al. (2013). Regulation of axon degeneration after injury and in development by the endogenous calpain inhibitor calpastatin. Neuron 80, 1175-1189.

Yool, D. A., Klugmann, M., Mclaughlin, M., Vouyiouklis, D. A., Dimou, L., Barrie, J. A., et al. (2001). Myelin proteolipid proteins promote the interaction of oligodendrocytes and axons. J. Neurosci. Res. 63, 151-164.

Young, K. M., Psachoulia, K., Tripathi, R. B., Dunn, S. J., Cossell, L., Attwell, D., et al. (2013). Oligodendrocyte dynamics in the healthy adult CNS: evidence for myelin remodeling. Neuron $77,873-885$.

Zalc, B. (2016). The acquisition of myelin: an evolutionary perspective. Brain Res. $1641,4-10$.

Zambonin, J., Engeham, S., Campbell, G. R., Ziabreva, I., Beadle, N. E., Taylor, R. W., et al. (2010). Identification and investigation of mitochondria lacking cytochrome c oxidase activity in axons. J. Neurosci. Methods 192, 115-120.

Zambonin, J. L., Zhao, C., Ohno, N., Campbell, G. R., Engeham, S., Ziabreva, I., et al. (2011). Increased mitochondrial content in remyelinated axons: implications for multiple sclerosis. Brain 134, 1901-1913.

Zhan, J., Mann, T., Joost, S., Behrangi, N., Frank, M., and Kipp, M. (2020). The cuprizone model: dos and do nots. Cells 9:843.

Zhang, C. L., Ho, P. L., Kintner, D. B., Sun, D., and Chiu, S. Y. (2010). Activitydependent regulation of mitochondrial motility by calcium and $\mathrm{Na} / \mathrm{K}$-ATPase at nodes of Ranvier of myelinated nerves. J. Neurosci. 30, 3555-3566.

Zhang, P., Kishimoto, Y., Grammatikakis, I., Gottimukkala, K., Cutler, R. G., Zhang, S., et al. (2019). Senolytic therapy alleviates Abeta-associated oligodendrocyte progenitor cell senescence and cognitive deficits in an Alzheimer's disease model. Nat. Neurosci. 22, 719-728.

Zhang, Y., Yuen, S., Peles, E., and Salzer, J. L. (2020). Accumulation of neurofascin at nodes of ranvier is regulated by a paranodal switch. J. Neurosci. 40, 57095723.

Zhao, C., Ma, D., Zawadzka, M., Fancy, S. P., Elis-Williams, L., Bouvier, G., et al. (2015). Sox2 sustains recruitment of oligodendrocyte progenitor cells following CNS demyelination and primes them for differentiation during remyelination. J. Neurosci. 35, 11482-11499.

Zhao, D., Feng, F., Zhao, C., Wu, F., Ma, C., Bai, Y., et al. (2018). Role of perforin secretion from CD8+ T-cells in neuronal cytotoxicity in multiple sclerosis. Neurol. Res. 40, 62-67.

Conflict of Interest: BE is a co-founder of Autobahn Therapeutics.

The remaining authors declare that the research was conducted in the absence of any commercial or financial relationships that could be construed as a potential conflict of interest.

Copyright (c) 2021 Duncan, Simkins and Emery. This is an open-access article distributed under the terms of the Creative Commons Attribution License (CC BY). The use, distribution or reproduction in other forums is permitted, provided the original author(s) and the copyright owner(s) are credited and that the original publication in this journal is cited, in accordance with accepted academic practice. No use, distribution or reproduction is permitted which does not comply with these terms. 